\title{
Clinical and Pre-Clinical Evidence of Carbonic Anhydrase IX in Pancreatic Cancer and Its High Expression in Pre-Cancerous Lesions
}

\author{
Sabina Strapcova ${ }^{1}$, Martina Takacova ${ }^{1}$, Lucia Csaderova ${ }^{1}$, Paola Martinelli ${ }^{2,3}$, \\ Lubomira Lukacikova ${ }^{1}$, Viliam Gal ${ }^{4}$, Juraj Kopacek ${ }^{1}$ and Eliska Svastova ${ }^{1, * \mathbb{D}}$ \\ 1 Department of Tumor Biology, Institute of Virology, Biomedical Research Center, Slovak Academy of \\ Sciences, Dubravska cesta 9, 84505 Bratislava, Slovakia; sabina.strapcova@gmail.com (S.S.); \\ martina.takacova@savba.sk (M.T.); lucia.csaderova@savba.sk (L.C.); lubomira.lukacikova@savba.sk (L.L.); \\ virukopa@savba.sk (J.K.) \\ 2 Institute of Cancer Research, Clinic of Internal Medicine I, Medical University of Vienna, \\ 1090 Vienna, Austria; paola.martinelli@boehringer-ingelheim.com \\ 3 Cancer Cell Signaling, Boehringer-Ingelheim RCV Vienna, A-1121 Vienna, Austria \\ 4 Alpha Medical Pathology, Ruzinovska 6, 82606 Bratislava, Slovakia; viliam.gal@gmail.com \\ * Correspondence: viruelis@savba.sk
}

Received: 22 June 2020; Accepted: 16 July 2020; Published: 22 July 2020

check for updates

\begin{abstract}
Hypoxia is a common phenomenon that occurs in most solid tumors. Regardless of tumor origin, the evolution of a hypoxia-adapted phenotype is critical for invasive cancer development. Pancreatic ductal adenocarcinoma is also characterized by hypoxia, desmoplasia, and the presence of necrosis, predicting poor outcome. Carbonic anhydrase IX (CAIX) is one of the most strict hypoxia regulated genes which plays a key role in the adaptation of cancer cells to hypoxia and acidosis. Here, we summarize clinical data showing that CAIX expression is associated with tumor necrosis, vascularization, expression of Frizzled-1, mucins, or proteins involved in glycolysis, and inevitably, poor prognosis of pancreatic cancer patients. We also describe the transcriptional regulation of CAIX in relation to signaling pathways activated in pancreatic cancers. A large part deals with the preclinical evidence supporting the relevance of CAIX in processes leading to the aggressive behavior of pancreatic tumors. Furthermore, we focus on CAIX occurrence in pre-cancerous lesions, and for the first time, we describe CAIX expression within intraductal papillary mucinous neoplasia. Our review concludes with a detailed account of clinical trials implicating that treatment consisting of conventionally used therapies combined with CAIX targeting could result in an improved anti-cancer response in pancreatic cancer patients.
\end{abstract}

Keywords: carbonic anhydrase IX; pancreatic cancer; intraductal papillary mucinous neoplasia; acidic microenvironment; hypoxia; correlation analysis; immunohistochemistry

\section{Introduction}

To date, several members of the carbonic anhydrase (CA) family namely CAI, CAII, CAIV, CAVB, CAVI, CAIX, and CAXII, have been identified in the human pancreas. Within the organ, CAs localize in alpha cells of Langerhans's islets (cytosolic CAI [1]), beta cells of the pancreas (mitochondrial CAV [2]), acinar cells (secreted CAVI [3], transmembrane CAXII [4]), and pancreatic ducts (cytosolic CAII [1,5], transmembrane CAIX [6,7], transmembrane CAXII [4]). CAXIV has no expression in healthy pancreas, but it has been found in pancreatic tumors [8] (Figure 1).

As with most carbonic anhydrases, CAIX catalyzes a simple physiological reaction, the reversible hydration of carbon dioxide to bicarbonate ions and protons. Hence, this exofacial CA located at the 
cell membrane is a crucial component of the $\mathrm{pH}$-regulating machinery in tumors [9-11]. To prevent the build-up of acidic metabolites inside cancer cells and to maintain a permissive intracellular $\mathrm{pH}$ for cell proliferation and survival, CAIX closely cooperates with the bicarbonate transporters NBCe1 and $\mathrm{NBCn1}$, catalyzing $\mathrm{HCO}^{3-}$ influx [12,13]. This functional interaction increases the efficiency of ion transport through a plasma membrane, generation of $\mathrm{pH}$ gradient, and neutralization of intracellular space. Together with CAIX, monocarboxylate transporters (MCTs) are also thought to participate in the process of extracellular acidification by exporting lactate and ions [14].

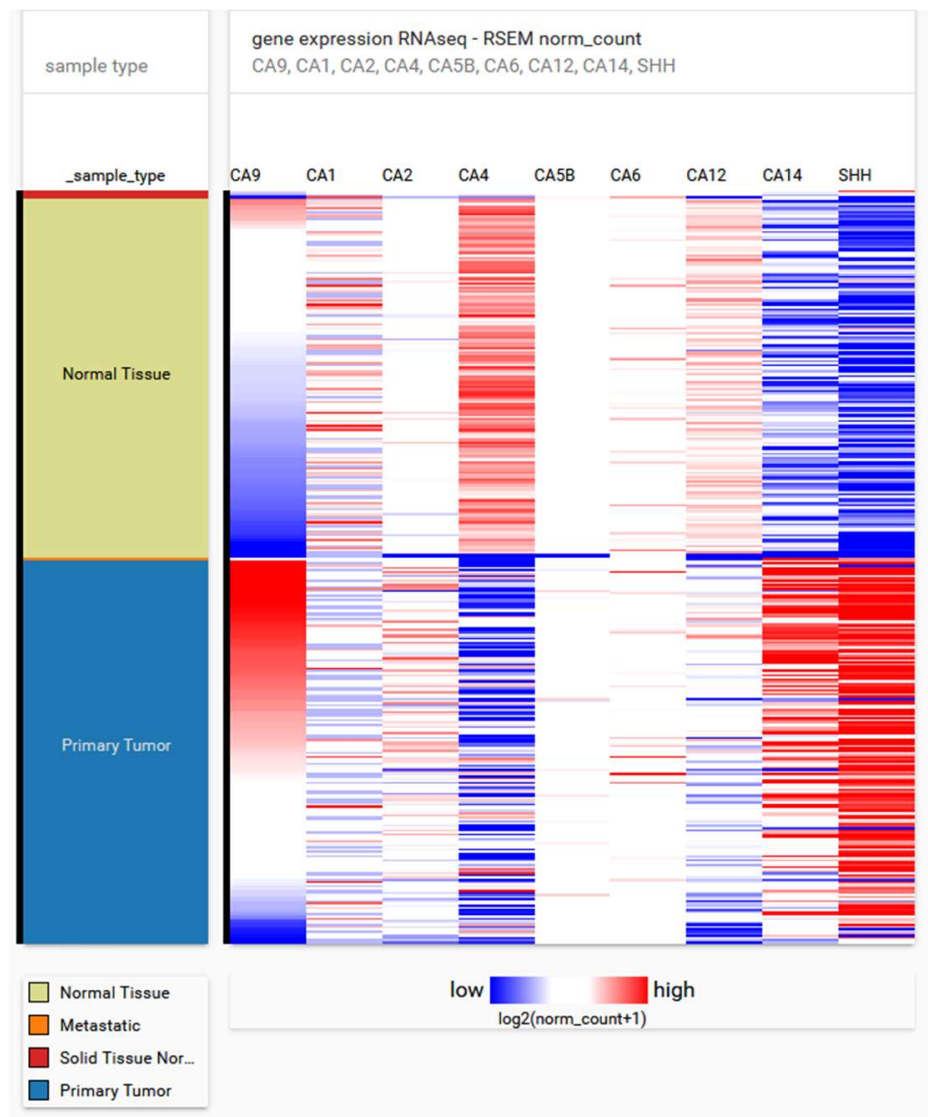

Figure 1. The expression profile of selected carbonic anhydrase isoforms and sonic hedgehog (activated in pancreatic cancer) in 179 samples of pancreatic adenocarcinoma and 171 normal pancreatic tissue samples extracted from Xena (using the cancer genome atlas (TCGA) target GTEx datasets) [15] (for more information see Supplementary Material). Expression of CA9 increases in pancreatic ductal adenocarcinoma samples along with Sonic Hedgehog (SHH) level. Analysis of CA9 promoter revealed possible regulation through Sonic Hedgehog (SHH) pathway (see Figure 2). According to the carbonic anhydrase nomenclature, human CA isoenzymes are written in capital Roman letters and numerals, while their genes are written in Italic letters and Arabic numerals.

The reversed intracellular $(\mathrm{pHi})$ and extracellular $\mathrm{pH}(\mathrm{pHe})$ gradient generated by the cooperation of CAIX with other proteins enhances cell migration, during which CAIX relocalizes to lammelipodia [12]. Invadopodial distribution of CAIX promoting the proteolytic activity of matrix metalloproteasis within invasion through the extracellular matrix and quail chorioallantoic membranes, as well as the ability of anti-CAIX antibodies to cease this process, was shown by Debreova et al. (2019) [16] (the role in invadopodia was also described in [17]). Furthermore, CAIX de-stabilizes cell-cell adhesion through competitive binding with $\beta$-catenin, disabling the formation of a complex between $\beta$-catenin and E-cadherin necessary for adherent junction maintenance. The disruption of this complex facilitates tumor cell dissemination and further cancer progression $[16,18]$. Interestingly, CAIX is also 
cleaved from the cell membrane by a disintegrin and metalloproteinase 17 (ADAM17). Its ectodomain serves as a potential blood biomarker of some cancer types with developed hypoxia $[19,20]$.

Considering its unique transcriptional regulation and expression, enzymatic activity, as well as appertaining functions [21], CAIX possesses a special position among all human CAs and is a crucial player implicated in cancer pathogenesis due to its catalytic and non-catalytic mechanisms. While enzymatic activity is mediated by the protein's catalytic CA domain oriented towards the extracellular space, the unique presence of a proteoglycan-like (PG) domain enables non-catalytic functions characteristic of CAIX. The PG domain is negatively charged and easily dissociates from complexes at a slightly acidic $\mathrm{pH}$ [22], facilitating the detachment of primary tumor cells, and eventually leading to the formation of metastases. Through its PG domain, CAIX facilitates adhesion to collagen. During initial adhesion and spreading, it colocalizes with paxillin in focal contacts [23]. Moreover, the PG domain displays the capability to bind mucins, abundantly overexpressed in pancreatic tumors.

The expression pattern of CAIX clearly differs from the rest of its CA family members: CAIX can be found in only a few normal tissues, but its ectopic expression is strongly connected with many cancer types, primarily due to the presence of hypoxia. The unique localization of a hypoxia response element ensures that CA9 belongs to the group of genes with the strongest hypoxia response executed via hypoxia-inducible factor 1 (HIF-1) [24]. In pancreatic cancer tissue, CAIX expression is higher compared to the healthy organ and precursor lesions [25-27] and positively correlates with tumor size and staging [26]. Particularly strong CAIX staining can be observed in areas of pancreatitis adjacent to the invading tumor [25]. High CAIX expression serves as an indicator of worse prognosis [26], but particularly poor prognosis was shown for pancreatic ductal adenocarcinoma (PDAC) patients with high levels of both CAIX and MCT4 in the stroma [28]. In patient-derived xenograft models of pancreatic cancer, CAIX was shown to be a key modulator of cancer initiation and tumor growth [29].

At time of diagnosis, $11 \%$ of pancreatic cancers are confined to their primary site and $52 \%$ have already metastasized [30]. While the relative 5-year survival for localized pancreatic cancer is $39.4 \%$, for cases staged as distant at diagnosis it is only 2.9\% [30]. PDAC is the most common neoplasm of the organ, accounting for $85 \%$ of all histologically-confirmed pancreatic cancer cases [31]. This particular subtype of pancreatic cancer has a very poor prognosis-24\% of patients live 1 year after diagnosis and only $9 \%$ are still alive after 5 years [32].

Even though the 5-year relative survival rate for all pancreatic cancer cases has quadrupled in the last 45 years, it currently remains at a dismal rate of 10\% [30], with life expectancy at the time of diagnosis an alarming 4.6 months [33]. With the lowest survival rate of all types of cancer in Europe [34], pancreatic cancer is responsible for more than 95,000 deaths in the EU every year [35]. By the year 2040, the number of cases of pancreatic cancer worldwide is predicted to rise by almost $80 \%$ [36].

An established model of pancreatic carcinogenesis resulting in the development of PDAC includes three morphologically-distinctive precursor lesions: pancreatic intraepithelial neoplasia (PanIN), intraductal papillary mucinous neoplasm (IPMN), and mucinous cystic neoplasm (MCN) [37]. PanINs arise from pancreatic ducts and are characterized by mucin-containing cuboidal to columnar cells and are graded (PanIN I-III) on the basis of histological and cytological criteria; high-grade PanINs ultimately transform into PDAC [38]. While roughly $40 \%$ of PanIN I lesions harbor a K-ras mutation $[39,40]$, inactivating mutations of CDKN2A, TP53, and SMAD4 have a rising incidence with higher PanIN grades [38]. IPMNs (mucin-producing non-invasive neoplasms) usually have a papillary architecture and can arise from the main pancreatic duct or branch ducts. While at cellular level they resemble PanINs, they have the ability to grow into larger cystic structures [41]. The excellent prognosis of IPMNs critically worsens once they progress to invasive carcinoma (40\% of IPMN) [42].

One of the reasons accounting for the lethality of pancreatic cancer is its intrinsic or acquired therapy resistance, whose the underlying mechanisms have already been reviewed in [43-45]. The major factors contributing to decreased therapeutic efficacy in this malignancy include hypoxia [46] and metabolic reprogramming — both indisputably linked to CAIX expression [47]. Intratumoral hypoxia 
not only hinders radiotherapy, but also chemotherapy and immunotherapy [48-51]. CAIX also aids microenvironmental acidification and lactate accumulation, which, in turn, leads to the suppression of the T-cell adaptive immune response and to an overall immune destruction escape [52]. Alterations in $\mathrm{pH}$ values within the tumor mass (namely the reversed $\mathrm{pH}$ gradient across cell membranes), which are maintained by CAIX in cooperation with other proton pumps and proton transporters, correlate with multi-drug resistance [53].

\section{Signaling Pathways Activated in Pancreatic Tumors and Their Relationship to Transcriptional Regulation of CA9}

The expression of CA9 is critically dependent on the transcription factors (TFs) and their binding sites, which are located within the promoter sequence localized approximately 170 nucleotides upstream from the transcription start site (TSS). A unique localization of a hypoxia response element (HRE) in position -10/-3 from TSS ensures that CA9 belongs to the group of genes with the strongest hypoxia response, which is executed via hypoxia-inducible factor 1 (HIF-1) [24]. HIF-1 is a protein complex composed of two constitutively-expressed $\alpha$ and $\beta$ subunits, from which the former one is oxygen sensitive. Under hypoxic conditions, $\beta$ subunit dimerizes with $\alpha$ subunit, leading to the formation of the heterodimeric TF HIF-1, which recognizes and binds the HRE regions of its target genes and upregulates their expression.

Therefore, HRE sequence is the most critical regulatory element within the CA9 promoter, while HIF-1 is a central regulator of CA9 transcription. Several studies have reported that hypoxia is evident in PDAC, in which the expression of HIF-1 $\alpha$ and CAIX have been detected in 60-70\% and $78 \%$ of cases, respectively [25,54,55]. Moreover, Hiraoka et al. confirmed CAIX expression in and around the necrotic lesions and suggested that histological necrosis could be a simple and reproducible predictor of postoperative outcome in PDAC patients [56]. In contrast to previous studies, no correlation between HIF-1 $\alpha$ and CAIX expression levels were found by Leppänen and colleagues and, moreover, weak HIF-1 $\alpha$ expression indicated poor prognosis for 69 patients with resectable PDAC [57]. A possible explanation for such discrepant findings about the prognostic role of HIF-1 $\alpha$ could lie in the methodology of immunohistochemistry, as well as in the primary antibodies used.

Besides HIF-1 and its binding within the HRE sequence, the core CA9 promoter contains additional binding elements for several TFs whose binding has already been confirmed (e.g., SP1, AP1 and AP2, ETS-1), or is still waiting for identification [58-60]. In addition to hypoxia, CA9 expression is elevated by high cell density and is modulated by the PI3K (phosphatidyl inositol 3-kinase) and MAPK (mitogen-activated protein kinase) pathways [61,62] (Figure 2).

Although several studies have been interested in the immunohistochemical staining of CAIX within pancreatic tumors, very little is known about the transcriptional regulation of CA9. So far, the major concern has been to study and affect hypoxia and HIF-1 presented in pancreatic tumor cells. For that reason, CA9 mRNA as well as CAIX protein expression as an exclusive HIF-1 target were analyzed. This example represents a specific small-molecule inhibitor-APX3330 (also called E3330) — of AP endonuclease1/Redox effector factor 1 (APE1/Ref-1), which was confirmed to reduce oxidized TFs and consequently to target the downstream signaling pathways. Fishel and colleagues showed that blocking APE1/Ref-1 redox signaling via E3330 leads to a decrease in TF activity of NF-кB, AP-1, and HIF-1 $\alpha$ in vitro [63]. Dose-dependent inhibition of the HIF-1 signaling pathway after the treatment of Panc-1 and PaCa-2 cells with E3330 was confirmed on the CA9 mRNA level using real-time quantitative reverse transcription PCR (qRT-PCR). Moreover, a combination treatment with APE1/Ref-1 inhibitor E3330 and CAIX inhibitor SLC-0111 (Clinical Trial NCT02215850) was shown to reduce proliferation and size of three-dimensional spheroids derived from PDAC patients [64]. In line with these findings, the application of novel analogues of both APE1/Ref- 1 and CAIX inhibitors (namely APX2009, APX2014, and FC12-531A) with improved potency significantly affected pancreatic cancer cell survival [65]. 


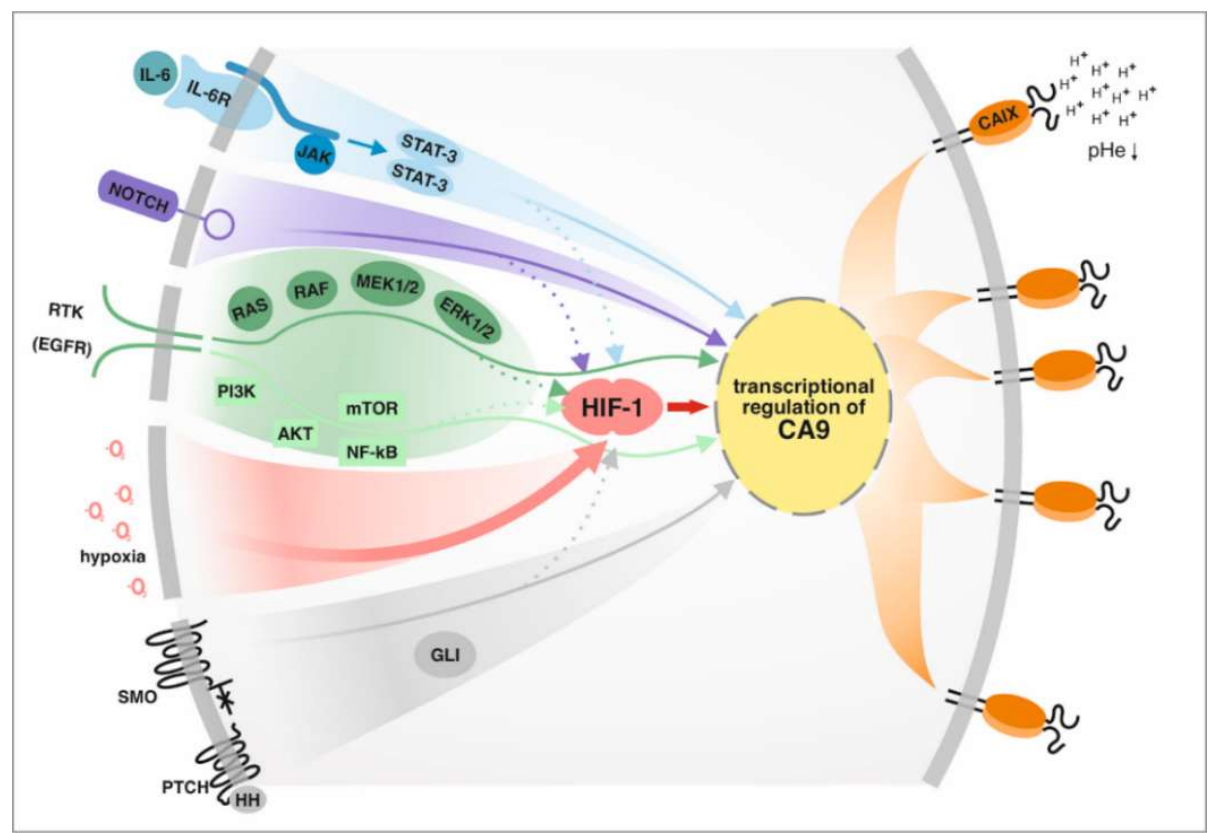

Figure 2. Schematic presentation of signaling pathways activated in pancreatic cancer and their effect on CA9 expression.

Key players contributing to pancreatic cancer development and progression are inflammatory cytokines produced by tumor and inflammatory cells, as well as cancer associated fibroblasts. Paracrine signaling plays a critical role in the whole secretome regulating desmoplasia and pancreatic cancer behavior. Soluble mediators like IL-6, IL-8, IL-1 $\beta$, TGF- $\beta$, TNF- $\alpha$, VEGF, SHH, etc. have been implicated in pancreatic cancer carcinogenesis [66]. A multifunctional cytokine interleukin (IL)-6 which activates upon binding to its receptor, a Janus kinase (JAK) family of tyrosine kinases and consequently stimulates multiple signaling pathways, e.gi. MAPK, PI3K, STAT [67], was shown to induce also CA9 expression. Using the model of human mammospheres, Sansone and collaborators revealed IL-6-induced Notch-3-dependent up-regulation of CAIX promoting the malignancy in breast cancer stem cells [68]. Moreover, they demonstrated that an interplay between p66Shc and Notch-3 regulates hypoxia response (via upregulation of CAIX) and the control of stem cell survival (via upregulation of the Notch ligand Jagged-1) [69]. In line with previous data, the relevance of co-operation between the intracellular domain of Notch-3 (NICD) and HIF-1 $\alpha$ for CA9 expression (at the level of mRNA, protein, and reporter) was described in breast cancer cells [70]. Enhanced cancer cell growth rates and invasiveness in an IL-6-dependent manner (through activation of Notch-3, Jagged-1, and CAIX via STAT-3) was reported by Studebaker [71]. In accordance with the results gained for breast cancer, a positive correlation between phosphorylation of STAT-3, Her-2 status, CAIX expression, and prognosis was observed in a large cohort of esophageal carcinomas [72]. Given the reported involvement of IL-6 in upregulation of CAIX expression in multiple previously-mentioned cancer models, it seems plausible that IL-6 signaling could also be implicated in the transcriptional regulation of CA9 in precursor lesions as well as in primary pancreatic tumors.

In addition to IL-6, STAT-3 can be activated by another receptor and non-receptor tyrosine kinases, such as epidermal growth factor receptor (EGFR), whose overexpression in pancreatic tumorigenesis has been implicated in neoplastic precursors and additionally, after tumor initiation, in the maintenance of MAPK/ERK activity [73,74]. Similarly to MAPK/ERK, PI3K/AKT represents another downstream signaling pathway which mediates the biological response of the EGFR. Both above-mentioned signaling pathways were previously reported to be involved in the transcriptional regulation of CA9 under hypoxia and high cell density $[61,62]$. In line with this, McDonald and colleagues showed that K-ras knockout pancreatic cancer cells reduced the protein level of HIF- $1 \alpha$, CAIX, and glycolysis in response 
to hypoxia [75]. Interestingly, knocking out K-ras as well as treatment with the mitogen-activated protein kinase (MEK) inhibitor trametinib lowered HIF-1 $\alpha$, CAIX, and phosphorylation of ERK1/2 even in normoxia. Hypoxia is a major pathophysiologic stimulus for upregulation of CA9 in solid tumors. However, HIF- $1 \alpha$ expression can also be stabilized/induced through other effectors and pathways, including PI3Kinase and mammalian target of rapamycin (mTOR), mutations in the tricarboxylic acid proteins such as fumarate hydratase, and gemcitabine [75].

It is well known that hypoxia plays a crucial role in cancer epithelial-to-mesenchymal transition (EMT) and invasion. A possible explanation of how hypoxia may contribute to these events lies in the activation of the hedgehog $(\mathrm{HH})$ signaling pathway. While the $\mathrm{HH}$ pathway is normally quiescent in adult pancreatic tissue, it has been shown to activate in pancreatic cancer cells where it promotes stromal hyperplasia and the production of the extracellular matrix (as reviewed in [76,77]). Bailey and colleagues revealed that Sonic Hedgehog $(\mathrm{SHH})$ expression promotes a desmoplastic reaction in pancreatic cancer [78]. Interestingly, Spivak-Kroizman and collaborators revealed that elevated secretion of SHH ligand by cancer cells (mediated via HIF- $1 \alpha$ ) could be responsible for the prevalence of desmoplasia in this type of cancer. In line with this, elevated levels of HIF- $1 \alpha$ and HH were found in pancreatic tumors and identified as markers of decreased patient survival [79].

SHH and downstream components of the HH pathway have been shown to be upregulated in precursor lesions and primary pancreatic tumors, but not in the normal pancreas [80]. Moreover, analysis of the HH pathway in IPMN tissue and xenografts showed that activation of the hedgehog signaling pathway represents an important step in the development of IPMN [81,82]. Interestingly, the nuclear expression of GLI1 was described to be elevated upon exposure to hypoxia, suggesting that GLI1 transcription factor could directly mediate hypoxia-induced EMT and invasion [83]. Several studies have revealed that a crosstalk between hypoxia and $\mathrm{HH}$ pathways within pancreatic cancer cells is operated in a ligand-independent manner and that the nuclear accumulation of GLI1 could be triggered via other factors, such as TGF- $\beta$, K-ras, and receptor tyrosine kinase (RTK) (reviewed in [84]). Such a non-canonical mechanism of GLI activation could contribute to the development of several types of cancer. PDAC, characterized by a high incidence of activating K-ras mutations, represents an exclusive example of non-canonical induction of the $\mathrm{HH}$ signaling pathway.

Hypoxia has been shown to increase $\mathrm{HH}$ pathway activation through the upregulation of $\mathrm{SHH}$, Smoothened (SMO), and GLI1 transcription in a ligand-independent manner, leading to enhanced invasiveness of pancreatic cancer [85]. In addition, the expression of MMP9, which contributes to the invasiveness of pancreatic cancer cells, was revealed to be affected via the $\mathrm{HH}$ signaling pathway alone, and in combination with hypoxia $[85,86]$. GLI1 is a transcriptional activator of target genes, and is itself a transcriptional target of the HH pathway. As a member of the GLI-Kruppel family of zinc-finger containing TFs, GLI1 binds specifically to a 9-base pair DNA sequence 5'-GACCACCCA-3' within the target gene promoters [87]. Interestingly, only the two cytosine pairs flanking the central adenine within the consensus site are critical for GLI binding, whereas the other positions can tolerate a certain degree of flexibility [88].

Considering all previously-mentioned indications, we performed a comprehensive in silico analysis of the CA9 promoter sequence using JASPAR [89] and MatInspector [90,91] (Supplementary Material). Through the JASPAR database, we revealed three putative GLI binding sites within the CA9 regulatory sequence (relative profile threshold score was $80 \%$, two of them were upstream and one was located downstream from the TSS; Figure 3). However, using a MatInspector analysis of the same CA9 promoter sequence, we were able to reveal only one putative GLI binding site at position $-270 /-256$ upstream from the TSS, having the matrix similarity 0.938 and the highest core similarity 1. Such discrepancies could be explained by the sensitivity and specificity, as well as the matrix description, which do not reflect binding sites in their genomic context. Although all these binding sites could possibly be recognized by GLI transcription factor, it is important to mention that their functionality and relevance for CA9 transcription has to be verified experimentally. 
Interestingly, some indications supporting the role of the $\mathrm{HH}$ signaling pathway in upregulation of CA9 expression can be found in several clinical studies. Onishi and colleagues confirmed, using triple staining fluorescence immunohistochemistry of surgically-resected pancreatic cancer tissues, that GLI1 and SMO proteins are partially co-expressed with CAIX, a marker of hypoxia [85]. Furthermore, Couvelard and colleagues observed $48 \%$ stromal cell positivity for CAIX in a cohort of 50 patients, as well as CAIX-positive fibroblasts in PDAC-possessing fibrotic areas. Since stromal HIF-1 $\alpha$ expression in fibroblasts was detected in a very low proportion of PDAC patients, and positive correlation was revealed between stromal CAIX positivity and CAIX+ cancer cell areas (predominantly upregulated via HIF-1) [25], we can expect an additional regulatory mechanism (e.g., paracrine stimulation of CAIX expression in stromal cells), which is mediated via hypoxia-induced $\mathrm{HH}$ signaling from adjacent tumor cells. Taken together, all these data suggest that the expression of CAIX in precursor lesions, as well as in primary pancreatic tumors, could be at least partially affected by $\mathrm{HH}$ signaling pathway activity, either alone or in collaboration with hypoxia and HIF-1.
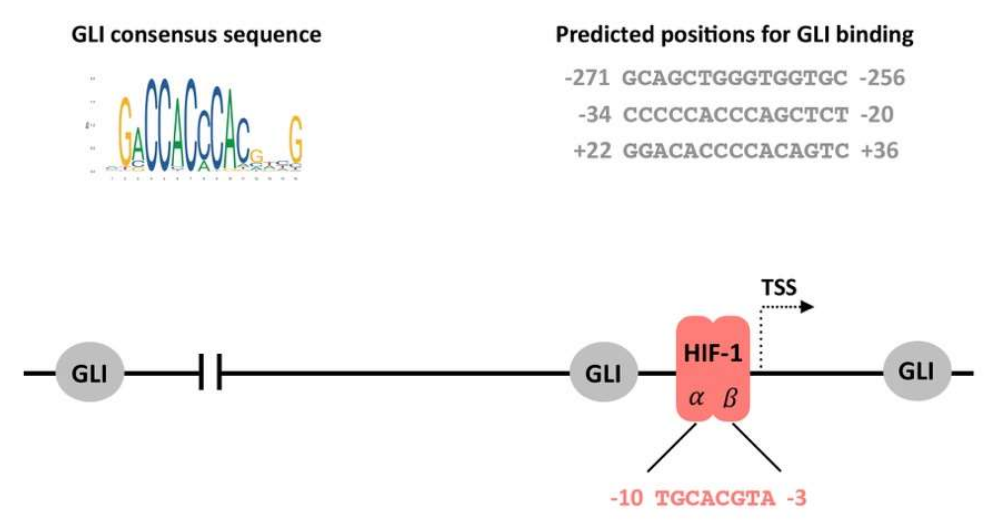

Figure 3. GLI consensus sequence (left side) and prediction of GLI binding sites (right side) within the CA9 promoter were acquired using JASPAR software. The position of three predicted GLI binding sites is outlined in relation to the hypoxia-responsive element (HRE; the sequence recognized by HIF-1 transcription factor) located $-10 /-3$ upstream from the transcription start site (TSS).

In conclusion, hypoxia and the transcription factor HIF-1 still remain the major transcriptional regulators of CA9 expression. However, the absence of correlation between HIF-1 and CAIX supports the hypothesis that rather than being regulated by hypoxia, CAIX expression could be induced by other signaling pathways and transcription factors. Therefore, the activity of IL-6/STAT-3, EGFR, MAPK, PI3K, as well as HH/GLI, which were all described as essential for pancreatic carcinogenesis, could be relevant for CA9 transcription and should be taken into consideration, especially in situations with no oxygen restrictions. Schematic presentation of signaling pathways relevant in pancreatic cancer and their effect on CA9 expression is illustrated in Figure 2.

\section{Inflammation as an Inherent Feature of Pancreatic Cancer and Its Impact on CAIX Expression}

The risk factors for pancreatic cancer development include genetic, environmental, and medical factors [92]. Pancreatitis, characterized by premature activation of digestive proenzymes and a subsequent autodigestion of the organ [93], remains the most significant risk factor, with the chance of pancreatic cancer development drastically increasing in patients with longer-standing chronic pancreatitis [92]. Even though only a minority of PDAC patients have a clinical history of pancreatitis [94,95], pancreatitis-induced stress was shown to cause acinar to ductal metaplasia [96-99] which can lead to the formation of PanIN lesions [100].

Damage-associated molecular patterns (DAMPs) are released upon stress, e.g., cellular injury, inflammation, or tissue damage [101] to stimulate toll-like receptors (TLRs), a subgroup of pattern recognition receptors (PRRs). TLRs enable cancer cells to undergo the switch from oxidative 
phosphorylation to glycolysis [102] and drive pancreatic stromal inflammation [103]. Toll-like receptor expression depends on PanIN grade [104], increases as cancer progresses [105], and is associated with metastases [106]. TLRs activate the NF-KB [101,107,108] and MAPK signaling pathways [108]. The subsequent cyclooxygenase (COX)-2 production [107] is vital for malignant transformation of normal cells, reduced apoptosis [109], invasion, and angiogenesis [110]. In pancreatic cancer, TLR activation also aids cancer cell proliferation and reduces chemosensitivity [105]. Through PGE2 synthesis and subsequent activation of the MAPK signaling pathway, COX-2 might upregulate CAIX expression and promote an aggressive cancer phenotype, similar to colorectal cancer cells where the expression of COX-2 and CAIX has been shown to correlate with each other and increase with tumor stage [111].

Inflammatory process initiation is further mediated by pro-inflammatory cytokines and chemokines, which can be released by acinar cells, neutrophils, monocytes, and eventually even by cancer cells, as well as other cells residing in the tumor microenvironment (TME). Inflammatory molecules such as IL-1, IL-6, TNF- $\alpha$, and TGF- $\beta$ [112-114] can activate pancreatic stellate cells which serve as a principal source of fibrosis [115]. The emerging fibrotic foci correlate with the presence of CAIX, localized in stromal fibroblast and in roughly $80 \%$ of tumors [25].

Crosstalk between TLR expression (i.e., innate immunity response, hypoxia, and CAIX expression) already exists in early pancreatic carcinogenesis [104]. The transcription factor HIF-1 $\alpha$ activates expression of several TLRs under hypoxic conditions [116-118]. The expressions of some TLRs and HIF- $1 \alpha$ correlate $[104,119]$ and prominent expression of HIF- $1 \alpha$, TLRs, and CAIX can be found as early as in PanINs [104]. Conversely, TLR3 was shown to induce the Warburg effect and aid tumor cells in adapting to the hypoxic milieu [102], whereas HIF-1 $\alpha$ and TLR4 may synergistically promote development of pancreatic cancer [119].

While the most potent regulator of CAIX expression is hypoxia, factors that can activate the transcription factor HIF-1 in normoxia include reactive oxygen species, succinate, and lactate [120]. In densely-grown cell cultures, minimal HIF-1 levels are required to initiate CAIX expression, as long as the transcription factor SP1 is present [58,62]. Similarly, the pro-inflammatory cytokine IL-6 is able to induce CAIX expression even in the absence of hypoxia [68]. CAIX is thought to be involved in promoting survival and enhancing the invasive behavior of cancer cells via the IL-6/Notch-3/CAIX axis [68].

Vast evidence suggests the involvement of CAIX in pancreatic cancer pathogenesis. Its localization at fibrotic sites and areas of pancreatitis, the ability to be induced in both a hypoxia-dependent and independent manner, the existence of crosstalk between CAIX and inflammatory molecules, as well as its correlation with necrosis, tumor grade, and poor prognosis [25] places CAIX in the center of pathological events leading from malignant transformation to pancreatic cancer progression and metastasis.

\section{Clinical Significance of CAIX in Pancreatic Cancer}

Expression of CAIX in non-neoplastic areas of the pancreas is very weak, while its abundance and intensity increase in pancreatitis regions close to invading tumors $[4,25,121]$. The rise in incidence and intensity of CAIX staining continues toward pancreatic ductal adenocarcinomas. The presence of CAIX in PDAC patients has been demonstrated in many papers, with its localization also detected in tumor and stromal cells. In a cohort of 50 patients with PDAC, Couvelard et al. showed CAIX positivity in $78 \%$ of cases [25]. Importantly, expression of CAIX correlated with fibrotic focus, which histologically reflects intratumoral hypoxia, replacing necrosis. Both the expression of CAIX and the presence of fibrotic focus were associated with lower survival. Interestingly, despite HIF- $1 \alpha$ positivity in $66 \%$ of patients, the authors claim no association between HIF- $1 \alpha$ and its downstream targets CA9 and VEGF, or clinicopathological variables. Similarly, immunohistochemical analysis of PDAC patient tissues confirmed the association of CAIX positive areas with necrosis, as a consequence of hypoxic occurrence. When micro- and macro-necrosis were taken into account, more than $60 \%$ of samples 
displayed necrotic areas. CAIX expression and necrosis were significantly associated with shorter disease-free survival and disease-specific survival, and were independently worse prognostic factors in a cohort of 348 PDAC patients [56].

Furthermore, CAIX expression was also associated with VEGF and with an increased microvessel density (MVD). Studies evaluating the significance of vasculature as a prognostic factor of metastasizing emphasize that a combination of $\alpha$-SMA and CD34 (MVD marker), indicating microvessel integrity, is more critical for cancer cell invasion and their dissemination through blood vessels. In patients with high MVD coupled with high microvessel integrity (high $\alpha$-SMA), the metastatic probability could be low [122]. A total of 179 pancreatic cancer patients were divided into 4 subgroups of different microvessel integrity (MVI). The largest HIF-1 $\alpha$ and CAIX density was detected in two subgroups with the worst overall survival (OS) and low microvessel integrity (low $\alpha$-SMA, high MVD and low $\alpha$-SMA, low MVD), where only $30 \%$ of patients survived the 7 -month time point. Conversely, the lowest intensity of HIF- $1 \alpha$ and CAIX was in the subgroup with high MVI (high $\alpha$-SMA, high MVD), with more than $90 \%$ of patients still alive at the 18 -month time point. Similar results were confirmed in hepatocellular carcinoma, which are highly vascularized in contrast to pancreatic cancer, emphasizing the importance of MVI instead of CD34-based vascularization in tumor recurrence and metastasis [122].

A prognostic gene signature was derived for patients suffering from early-stage PDAC, using overall survival as a primary endpoint [123]. The set is comprised of 15 genes whose higher expression was associated with poor overall survival. Six genes (IGF2BP3, KIF14, PPBP, SERPINB5, SLC2A1, TMPRSS3) out of 15 were linked with differing outcomes in other independent studies, indicating the possibility of using the signature as a prognostic tool specific to PDAC. Our in silico analysis of 179 PDAC samples and 171 normal pancreas samples derived from the cancer genome atlas (TCGA) and GTEx datasets showed upregulation of all analyzed genes as well as CA9 in tumor samples compared to healthy tissues (Figure 4A). We detected a positive correlation of CA9 expression with all 15 genes of the panel and with S100P, which is also implicated in PDAC tumorigenesis (Figure 4B). A correlation coefficient of 0.5 and higher was found between CA9 and more than $60 \%$ of the analyzed genes.

Research addressing the expression of arginase II (ARG2) in pancreatic cancer and its role in immune suppression revealed that the majority of ARG2 is present in cancer-associated fibroblasts (CAFs) in hypoxic state [124]. ARG2-expressing CAFs were located around necrosis with CAIX, GLUT1, and HIF-1 $\alpha$ positivity. Interestingly, areas of ARG2 and thus also CAIX-expressing CAFs significantly correlated with an immunosuppressive microenvironment identified by higher infiltration of $\mathrm{CD} 8^{+}$macrophages, $\mathrm{CD} 6 \mathrm{~b}^{+}$neutrophils, and lower infiltration of $\mathrm{CD} 4^{+} \mathrm{T}$ cells and $\mathrm{CD} 8^{+} \mathrm{T}$ cells. Increased ARG2 expression and a diminished number of tumor-infiltrating lymphocytes was also reported in prostate cancer [125]. It is probable that in reported cases of PDAC patients, the precise combination of increased ARG2 with a hypoxic TME, characterized by CAIX expression and known for its immunosuppressive properties, contributes to the inhibition of an anti-tumor immune response. This clinical study implies that CAIX protein through its impact on extracellular acidosis contributes to the inhibition of immune cell infiltration.

Epigenetic changes, which are strongly affected by hypoxia, are an important feature of cancer development and progression [126]. Hypoxia upregulates the expression of different DNA methylation and demethylation enzymes. Expression of CAIX as a hypoxia marker was also investigated in relation to the methylation status of mucins promoter regions, which are aberrantly produced and play a crucial role in pancreatic cancer carcinogenesis. Expression of MUC1, MUC4, and MUC5AC increases progressively with the advancement of pancreatic cancer, and is associated with poor survival [127]. Importantly, MUC1 and MUC4 modulate chemoresistance of pancreatic cancer cell lines in vitro. Their downregulation enhances sensitivity to gemcitabine, the leading chemotherapy in pancreatic cancers [128]. 
A

gene expression RNAseq - RSEM norm_count

sample type

CA9, C6orf15, CAPN8, HIST1H3H, IGF2BP3, KIF14, KRT6A, PMAIP1, PPBP, RTKN2, SCEL, SERPI

$\begin{array}{lllllll}\text { C6orf15 HIST1H3H } & \text { KIF14 } & \text { PMAIP1 } & \text { RTKN2 } & \text { SERPINB5 } & \text { SLC45A3 } & \text { UCA1 }\end{array}$

_sample_type

\begin{tabular}{lllllllll} 
CA9 & CAPN8 IGF2BP3 & KRT6A & PPBP & SCEL & SLC2A1 & TMPRSS3 & S100P \\
\hline
\end{tabular}
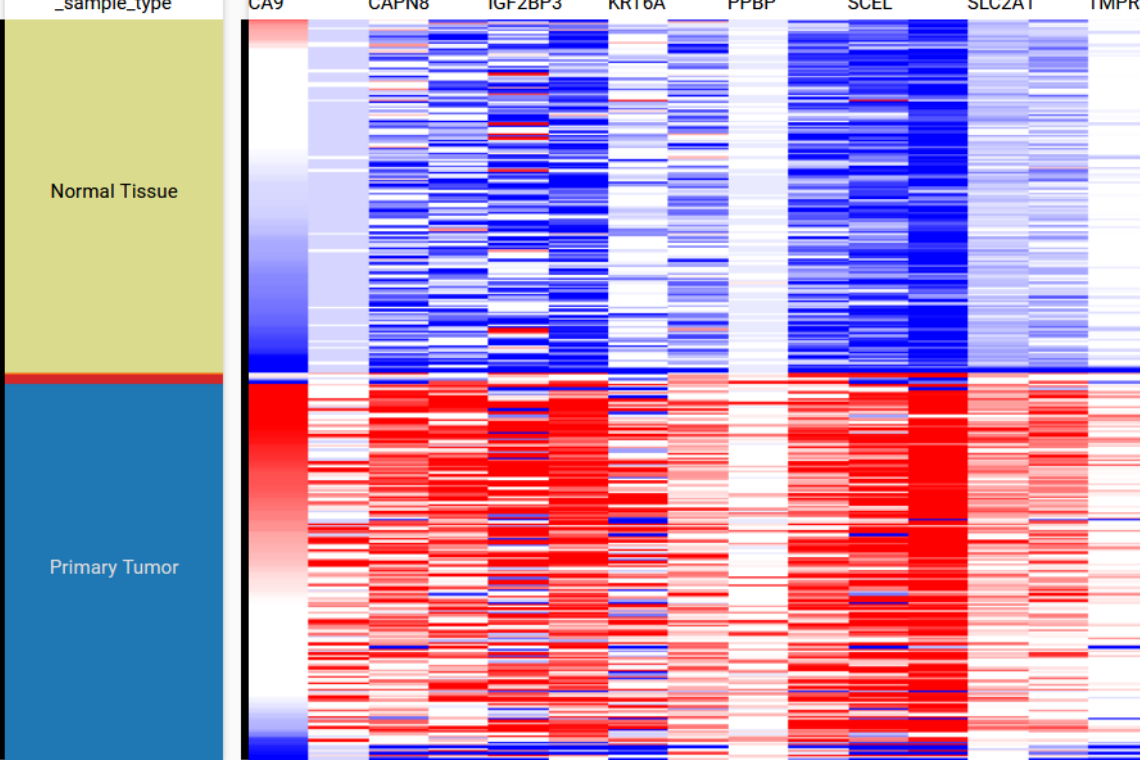

$\square$ Normal Tissue

$\square$ Metastatic

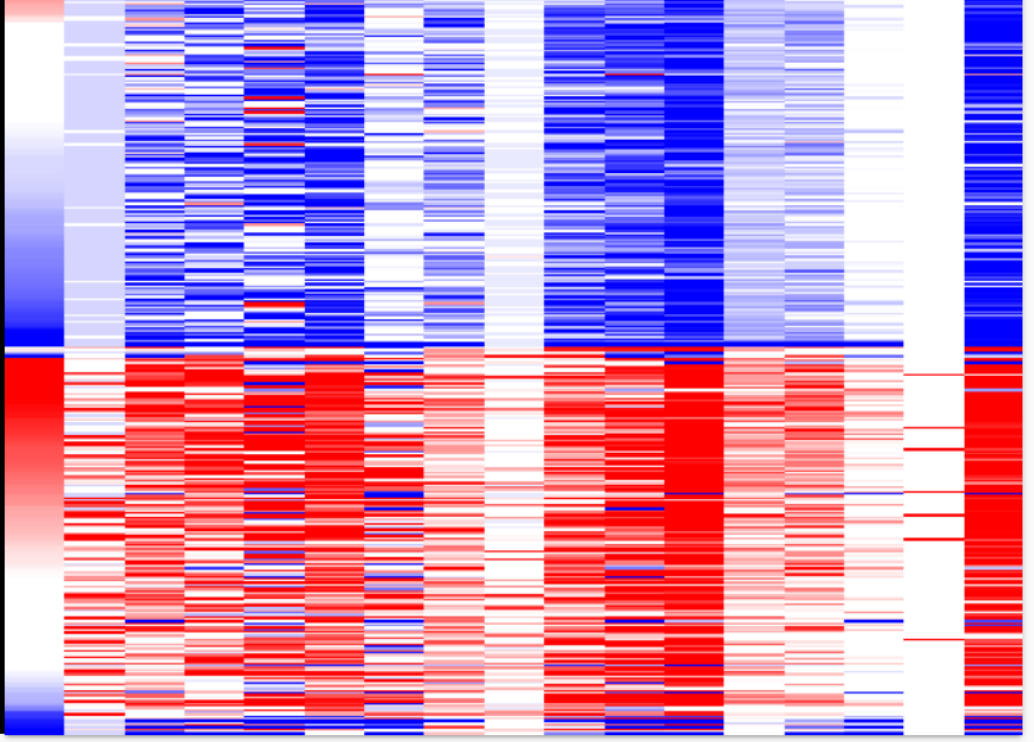

$\square$ Solid Tissue Nor

$\square$ Primary Tumor

\section{B}

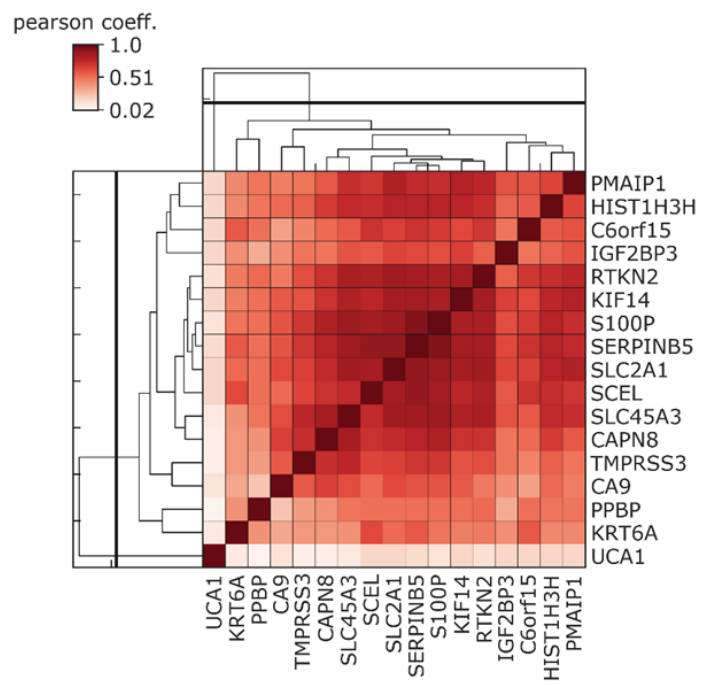

Figure 4. (A) The expression profile of CA9, S100P, and prognostic 15 gene signature panel for Early Stage Pancreatic Ductal Adenocarcinoma in 179 samples of pancreatic adenocarcinoma and 171 of normal pancreatic tissue extracted from Xena (TCGA target GTEx). (B) Pearson correlation coefficient diagram of analyzed genes. CA9 is positively correlated with the 15 gene signature panel as well as S100P (Supplementary Material). 
Yokoyama et al. revealed high correlation between the expression of CAIX, MUC1, and MUC4 in pancreatic cancer patients [129]. They showed that hypomethylation of MUC1 and MUC4 promoters correlates with mRNA and IHC positivity of both mucins in pancreatic cancer tissues, and with a high CA9 level. Analysis of overall survival showed that patients with hypomethylation of MUC1 and MUC4 display worse prognosis compared to those with hypermethylation. Furthermore, the correlation between CA9 expression as a hypoxic environment marker and DNA demethylation enzymes TET1 and TET2, and DNA methyltransferase DNMT3a, was confirmed in pancreatic neoplastic tissues. TET1, TET2, and DNMT3a also correlated with the hypomethylation status of MUC1 and MUC4, and with the development of distant metastasis. Thus, CAIX as a marker of hypoxic TME indicates tumor milieu, where epigenetic changes are one of the mechanisms regulating pancreatic cancer progression. Association of methylation status with expression of different mucins was also shown in breast, lung, pancreas, and colon cancer cell lines [130]. Global reduction of DNA methylation in hypoxic regions of tumors was clearly demonstrated in mouse xenografts of colorectal and melanoma cancers [131]. The authors found an inverse correlation between DNA methylation in cancer cells and their distance to perfused vessels. Contrarily, other studies reported that hypoxia promotes DNA hypermethylation in a panel of human cancers [132]. Importantly, Thienpont et al. reported that tumor suppressor genes and oncogenes are differently affected by hypoxia-induced DNA methylation, with strikingly more methylated promoters of tumor suppressor genes in hypoxic tumor areas [133].

In addition to hypoxia, hedgehog and Wnt signaling are improperly upregulated in pancreatic cancer, even in pre-cancerous lesions. Moreover, the Wnt cascade is also regulated by the hypoxia and hedgehog pathways. Canonical Wnt signaling is triggered by the complex formation of soluble Wnt ligands with their Frizzled receptors and LRP5/LRP6 co-receptors, resulting in $\beta$-catenin/TCF-LEF transcriptional activity. Activation of Wnt target genes facilitates proliferation, invasion, and EMT. Overexpression of Frizzled receptors (FZD1, 2, 7, 9) and their ligands (WNT2, 3, 4, 5A, 5B, etc.) was detected in pancreatic cancer patients compared to those with a normal pancreas. Importantly, downstream target genes of the Wnt pathway were also strongly upregulated (cyclinD1, fibronectin, MMP7, COX-2, uPAR, etc.), indicating activated Wnt signaling in PDAC [134]. Yang et al. showed that $56.6 \%$ and $54.7 \%$ of PDAC patients $(n=106)$ were positive for CAIX or FZD1, respectively [27]. The expression of FZD1 positively correlated with CAIX, whilst out of all FZD1 positive cases, 79\% had positive CAIX expression (as for FZD1 negative samples, 70\% were CAIX negative). The authors considered as positive those tissues that contained $\geq 25 \%$ immunohistochemically positive cells (they did not examine staining intensity). Based on this approach, expression of CAIX as well as FZD1 correlated with clinicopathological characteristics of pancreatic ductal adenocarcinoma such as TNM stage, lymph node metastasis, and lymph node invasion. Positive FZD1 and CAIX expression was significantly higher in PDACs than in precursor lesions or a healthy pancreas, and were associated with shorter overall survival.

Although FZD1 was undetected in the study by Zeng et al. [135], FZD2 and Wnt-1 were upregulated concurrently with $\beta$-catenin in around $65 \%$ of evaluated PDAC tumors. In accordance with the activated $\mathrm{Wnt} / \beta$-catenin pathway, they also showed a decrease in $\beta$-catenin phosphorylation (Ser45/Thr41) responsible for its degradation, with $\beta$-catenin/TCF complexes regulating gene transcription only detected in the nuclear extracts of tumors. Another mechanism of Wnt pathway activation described in pancreatic cancer is through the increased level of Disheveled-2 protein, a negative regulator of GSK3 $\beta$-axin complex, protecting $\beta$-catenin from degradation. Both ATDC and IQGAP1 proteins, recently described as overexpressed in PDAC patients, increase stability of DVL-2 with subsequent elevation of free $\beta$-catenin pool and its transcriptional activity. In primary pancreatic cancers, the level of ATDC correlates with DVL-2 and increased $\beta$-catenin [136]. Hu et al. proved the prognostic value of IQGAP1 expression in PDAC patients [137]. The group with a high IQGAP1 level displayed significantly poorer overall survival rates than the IQGAP1-low group. IQGAP1 directly interacts with DVL-2 and $\beta$-catenin, and promotes pancreatic cancer progression and EMT. In a previous work, we showed that CAIX protein co-precipitates with $\beta$-catenin, and ectopic expression of CAIX decreases 
the amount of cytoskeleton-linked E-cadherin, $\beta$-catenin, and $\alpha$-catenin proteins [18]. Thus, CAIX could facilitate pancreatic cancer through the destabilization of cell-cell adhesion and its involvement in Wnt pathway activation.

\section{CAIX in Pre-Cancerous Lesions of Pancreatic Ductal Adenocarcinoma}

Although several papers have reported that a high percentage of normal pancreas tissues express CAIX, it is important to note that this expression is very weak compared to the hyperplastic epithelium, PanIN, or PDAC lesions [25,57]. On the other hand, Kivelä and colleagues observed sporadically-expressed CAIX in the basolateral membranes of normal acinar and ductal epithelial cells, with an increasing and stronger immunoreaction in the hyperplastic epithelium adjacent to tumor tissue [4]. Yang et al. analyzed 55 precursor pancreatic lesions, where among the intraepithelial neoplasia, chronic pancreatitis and adenomas, the positive rate of CAIX was $20 \%$, $10 \%$, and $20 \%$ respectively [27]. Expression in normal pancreata was documented in $15.4 \%$ of cases. Discrepancies between individual articles mainly arise from different approaches to the evaluation of immunohistochemistry positivity (percentage of positive cells versus complex histoscore calculation), the immunohistochemistry procedure used, and from the use of different primary antibodies. A very detailed investigation of CAIX expression in PanINI to PanINIII was performed by Lepännen et al. [57]. Strong membranous CAIX positive staining was detected in 90\% of PanINI, 100\% of PanINII, and 94\% of PanINIII lesions. The histoscore of CAIX staining increased from PanINI to PanINIII. In contrast, normal acinar and duct cells were CAIX negative or weakly positive, although the positivity was declared in $84 \%$ of normal ducts. Importantly, the histoscore in normal pancreatic ducts is almost three times lower than in the most severe lesions (PanINIII). Similarly, nuclear HIF-1 $\alpha$ positivity was detected in around $80 \%$ of normal and preneoplastic PanIN lesions, but again the histoscore in PanINIII was significantly higher than in normal pancreatic ducts. It is important to note that all these stainings were performed on tissue sections of patients who had already developed pancreatic cancer with clinical manifestations. Paracrine factors produced within the TME combined with inflammatory cytokines might influence adjacent healthy cells compared to pancreata with PanINs but without cancer.

Besides the previously-mentioned PanINs, other types of pancreatic precursor lesions are intraductal papillary mucinous neoplasm and mucinous cystic neoplasm, which make up $20 \%$ of all PDAC precursors. Greater detail about the biology and genetics of IPMNs can be found in several reviews (e.g., [37,138]). Only one recent paper describes intensive immunostaining of CAIX in mucinous cystadenomas (benign cystic tumors with a risk of malignant progression) and weak to strong CAIX positivity in benign microcystic adenomas [27]. Transcriptomic profiling of 12 selectively-microdissected IPMNs observed CA9 as one of the most highly-expressed genes in IPMNs (17-fold increase) among the highest-ranked 100 known genes, as compared to normal pancreatic ducts [139]. Our Genevestigator analysis [140] also showed an increased CA9 level in samples of intraductal papillary mucinous adenoma, adenocarcinoma, and invasive carcinoma from patients with pancreatic cancer compared to normal pancreatic duct tissue (Figure 5). The CA9 upregulation ranges from 6-fold in adenocarcinoma and invasive carcinoma to an 11-fold change in the case of adenoma. 


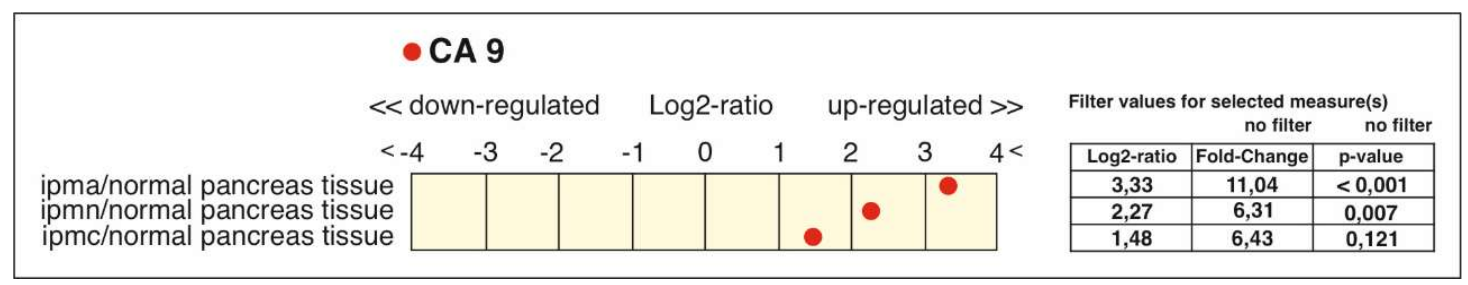

Figure 5. Upregulation of CA9 in intraductal papillary mucinous neoplasm (IPMN) samples compared to normal pancreatic tissue. The analysis was performed in Genevestigator (Nebion AG), a multi-organism microarray data analysis toolbox, using data from experiment No. HS-00705 (GSE19650) comprising 21 samples of intraductal papillary-mucinous adenoma (ipma, $n=6$ ), adenocarcinoma (ipmc, $n=6$ ), invasive carcinoma (ipmn, $n=3)$, and normal pancreatic duct tissue $(n=6)$. The graph shows a $\log$ fold change between various types of mucinous neoplasia tissues and healthy tissue samples; $p$ denotes significance of changes.

However, the immunohistochemical staining of CAIX in IPMNs has never been outlined before. Thus, we were interested in the immunohistochemical evaluation of CAIX expression in IPMNs which were identified in 5 cases from the cohort of 55 PDAC patients (Supplementary Material). As shown in Figure 6, all 5 IPMN samples were strongly CAIX-positive (predominant value 3 from the scale 0-3) and the percentage of CAIX-positive cells within IPMN lesions ranged from $20 \%$ to $90 \%$ (see table within Figure 6). Additionally, the IPMN region proportion within each tissue sample was evaluated, with all data summarized in Figure 6. Based on multiple evidence (expanded upon in Section 2, which discusses transcriptional regulation of CA9 in pancreatic tumors), high CAIX-positivity within IPMN could be affected by the activity of several signaling pathways relevant to the microenvironment of precursor lesions.

Interestingly, expression of glycolysis-associated genes which reflect adaptation to hypoxia or Warburg effect phenotype of cancer cells, characteristic of a CAIX-related TME, are already overexpressed in PanIN and IPMN lesions. Immunostaining positivity of PKM2 progressively increases from PanIN to pancreatic cancer. LDHA is strongly upregulated even in pancreatitis and there are no significant differences between chronic pancreatitis, PanIN, and cancer samples [141]. Furthermore, a considerable increase in LDHA and MCT4 staining was also observed in patients with IPMN lesions, mainly in those diagnosed with high-grade IPMN who later (after surgical resection of IPMN lesion) progressed to adenocarcinoma or whose resected pancreas specimens already contained IPMN-associated adenocarcinoma, compared to patients with only benign IPMN [142]. 


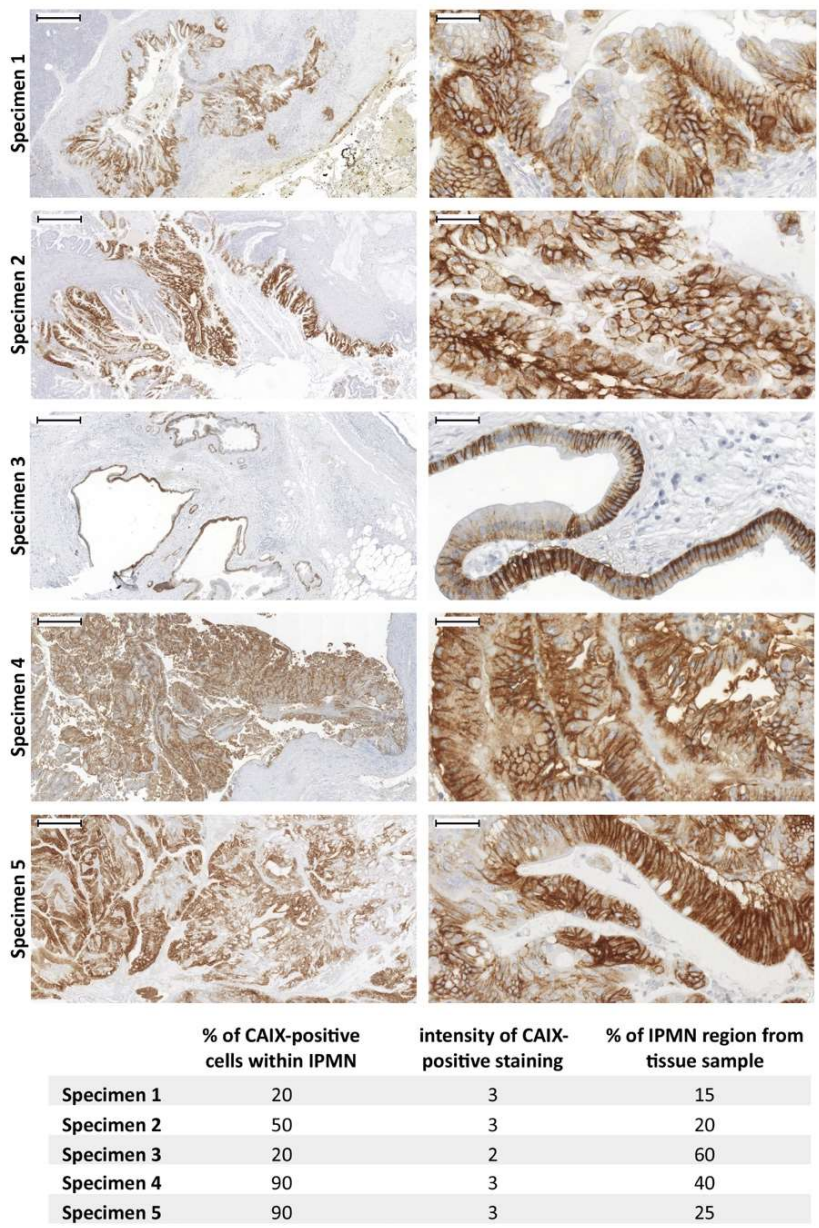

Figure 6. Immunohistochemical staining of CAIX in IPMN lesions within pancreatic ductal adenocarcinoma (PDAC) patient samples. The set of 5 IPMN tissue specimens were immunostained using the specific anti-CAIX monoclonal antibody M75 [143] as described previously [144] (Supplementary Material). Representative pictures taken from all 5 IPMN tissue specimens (left side) were complemented with detailed pictures (right side) describing CAIX-specific staining pattern (brown). All sections were counterstained with Mayer's hematoxylin (blue nuclei). Scale bar $500 \mu \mathrm{m}$ (left side) and $50 \mu \mathrm{m}$ (right side).

Using a large-scale profiling of gene expression among 12 intraductal papillary mucinous neoplasms with and without associated invasive carcinoma, Sato et al. identified a panel of genes significantly upregulated (fold change of 5 or more) in IPMN in comparison to healthy tissue samples and genes potentially linked to an invasive phenotype of IPMN [139]. Interestingly, multiple genes found among the most highly upregulated ones in IPMNs have been already reported as overexpressed in PDAC. Our in silico analysis of the GSE19650 dataset revealed that CA9 displays a high positive correlation with several of these genes (Figure 7), such as S100P (correlation coefficient 0.67), mesothelin MSLN (0.82), prostate stem cell antigen (PSCA) (0.82) and, to a lesser extent, with CD55 (0.46), TPM2 (0.35), and SERPINB5 (0.29). CA9 expression was also linked to glycolysis-related gene HK2 and genes coding proteins involved in $\mathrm{pH}$ regulation (anion exchanger 2 (AE2), sodium/hydrogen exchanger 1 (NHE1)). 


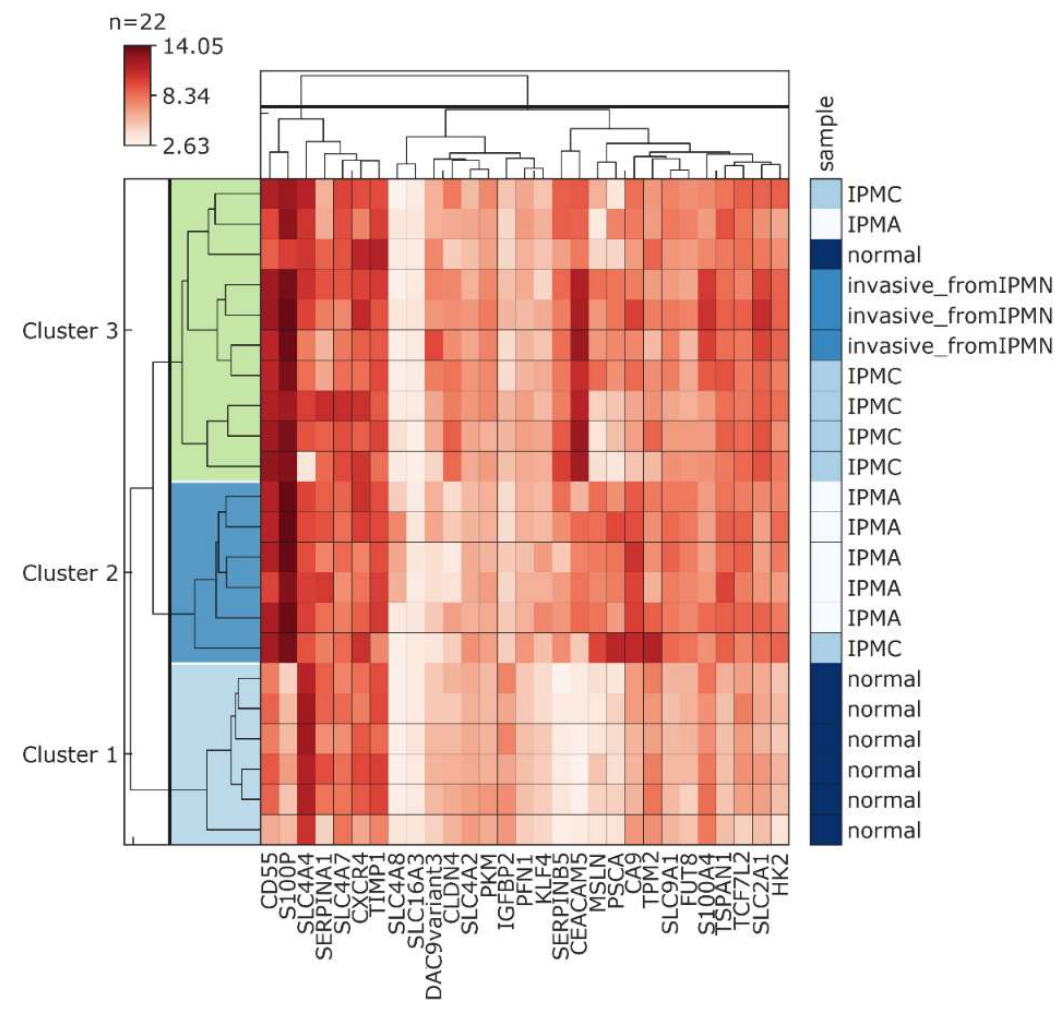

Figure 7. Hierarchical clustering of GSE19650 samples according to the panel of Genes Highly Expressed in IPMNs as Compared with Normal Pancreatic Ductal Epithelium and Genes Associated with Invasive Intraductal Papillary Mucinous Neoplasms of the Pancreas [139], selected pH regulators (SLC4A7, SLC4A4, SLC4A8, SLC4A2, SLC9A1), and glycolysis-related genes (HK2). Genes from the panel of Sato et al. (2004) as well as CA9 show a mutual correlation and a differential expression between normal healthy samples and IPMN samples. Hierarchical cluster analysis was able to correctly cluster the majority of normal healthy tissue samples into one cluster and all mucinous neoplasm samples were grouped into two clusters: cluster 2 contains mainly non-invasive adenoma samples, while cluster 3 includes the majority of adenocarcinoma with invasion and invasive carcinoma.

We also evaluated a possible relationship between CA9 expression and expression of immunityrelated genes which were significantly upregulated in pancreatic ductal adenocarcinoma patients with a good prognosis compared to patients with a worse prognosis [145]. Already in IPMN lesions, CA9 showed a varying degree of negative correlation, with the analyzed immune competent genes highly expressed in patients with a good outcome (Figure 8).

Notably, the TCGA analysis performed by McDonald et al. on 135 PDAC cases revealed that CAIX expression correlates with a set of genes associated with glycolysis including LDHA, monocarboxylate transporters (MCT4, MCT1), glucose transporters (GLUT1, GLUT4), and pyruvate dehydrogenase kinase 1 (PDK1) [75]. Patients with very low levels of CAIX and other selected hypoxia adaptation genes exhibited significantly longer survival compared to the group with high levels of expression. Based on tissue microarray staining, CAIX-positive tumors were identified in $66 \%$ of PDAC patients. Similarly, an association between CAIX and glycolysis was shown in breast cancer cells. Suppression of CAIX led to attenuation of glycolysis with reduction of PDK1 expression/function through LIN28/let-7 axis [146]. 


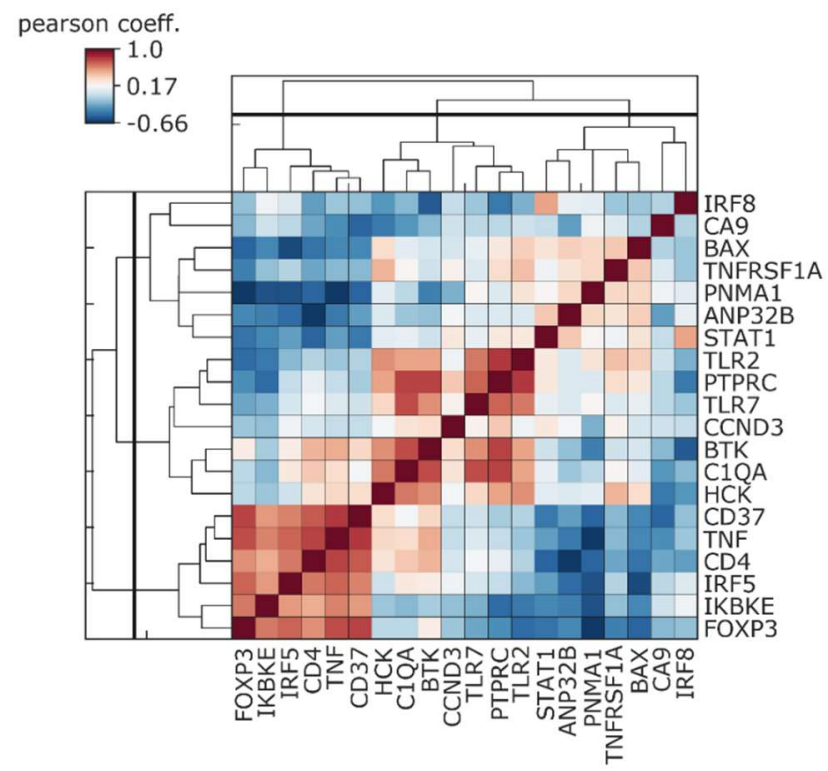

Figure 8. Negative correlation between CA9 and immune panel genes which are upregulated in samples with better prognosis. The analysis was performed with GSE19650 consisting of intraductal mucinous neoplasia and normal tissues. Immune gene panel indicates immune-related genes as predictors of outcome in pancreatic adenocarcinoma according to D'Angelo et al. [145].

Interestingly, the $\mathrm{pH}$-sensitive probe (pHLIP peptide) which was used to image PDAC xenografts was also able to detect PanIN lesions in genetically-engineered mouse models [147]. The pHLIPs are membrane peptides which insert themselves into the plasma membranes and form a transmembrane helix only within an acidic extracellular microenvironment. This is the first in vivo evidence of an acidic pancreatic cancer microenvironment even in pre-cancerous lesions. All these data suggest that CAIX could serve as a marker of pancreatic intraepithelial neoplasia. Importantly, another technique of imaging extracellular acidosis in the TME is acidoCEST-MRI (chemical exchange saturation transfer (CEST) magnetic resonance imaging) [148]. This non-invasive method, which uses a contrast agent and instrumentation routinely available in radiology clinics, can accurately measure tumor pHe with its spatial heterogeneity. AcidoCEST-MRI was successfully used to monitor changes in tumor acidosis of pancreatic cancer mice models. pHe significantly differed between the metformin-treated group and the control group due to the therapeutic efficiency of metformin, which counteracts glycolysis and thus pHe [148]. Furthermore, acidoCEST-MRI evaluating pHe in B-cell lymphoma xenografts showed strong correlation between extracellular acidity and CAIX expression [149]. Current progress in the in vivo measurement of microenvironmental acidosis of pancreatic adenocarcinomas is reviewed in [150].

Thus, whilst CAIX significantly contributes to extracellular acidosis of tumors, the imaging of tumor $\mathrm{pHe}$ in vivo using different $\mathrm{pH}$-sensitive probes or by specific anti-CAIX antibodies could lead to early detection of pre-malignant lesions which are undetectable by commonly used imaging techniques. In fact, the chimeric anti-CAIX antibody cG250 was shown to excellently detect CAIX-positive primary renal ccRCC tumors and their metastatic lesions in the human body [151].

Importantly, recent data from mouse models of PDAC and human PanIN lesions indicate that hypoxic microenvironments emerge early during pancreatic carcinogenesis. HIF- $1 \alpha$ and hypoxyprobe positivity was observed even in sporadic PanIN lesions from 2-month old K-rasG12D mice (p48-Cre; LSL-K-rasG12D autochthonous PDAC mouse model) without developed adenocarcinoma [152]. Nuclear HIF-1 $\alpha$ staining was also confirmed in PanINI to PanINIII lesions from human samples. These data suggest that CAIX expression, along with hypoxia response and acidosis, play a role in the early phase of pancreatic carcinogenesis. 


\section{Influence of CAIX Expression and CAIX-Associated Tumor Microenvironment on Therapy Resistance Explored in Preclinical Models of Pancreatic Cancer}

Poor response to anti-cancer therapies remains one of the main problems of pancreatic cancer. Hypoxia-in adverse feature of pancreatic cancer-mediates resistance to chemotherapy, radiotherapy, and immunotherapy, and creates the niche supporting the stemness of tumor-initiating cells (TICs).

Cooperation between hypoxia stimuli and paracrine signaling from an inflammatory environment, an inherent feature of pancreatic tumors, induces EMT, stemness, and promotes the formation of circulating tumor cells [126]. High CAIX expression was detected in tumor-initiating cells (TICs) positive for pancreatic cancer stem cell markers EpCAM ${ }^{+} / \mathrm{CD} 44^{+} / \mathrm{CD} 24^{+}$, isolated from PDAC patient samples [29]. Silencing of CA9 in the $\mathrm{EpCAM}^{+} / \mathrm{CAIX}{ }^{\text {high }}$ TICs population resulted in failed tumor initiating activity in mice xenografts. These data indicate that inhibition of CAIX with specific antibodies or inhibitors may impair tumor growth and metastasis.

Shukla et al. showed that HIF- $1 \alpha$-dependent high glycolytic flux is responsible for gemcitabine resistance in pancreatic cancer cells [153]. The mechanism behind this phenomenon is molecular competition between an increased cytidine pool and gemcitabine, which cannot be efficiently incorporated into the replicating DNA. HIF- $1 \alpha$ target genes, TKT and CTPS1, regulating pyrimidine synthesis are associated with primary and metastatic pancreatic cancer tissues. Importantly, inhibition of HIF- $1 \alpha$ - pharmacologically or genetically-improves gemcitabine sensitivity even in patient-derived xenografts (PDXs) in nude mice. TKT and CTPS1 co-localized with CAIX in PDAC tissue samples and in orthotopic pancreatic tumors. The authors hypothesize that hypoxia plays an important role in gemcitabine resistance in vivo through the modulation of TKT, CTPS1, and other glycolytic enzyme expression, whilst CAIX is the component of this microenvironment. Co-expression of CAIX with HK2, a surrogate marker of HIF- $1 \alpha$ activation, was detected in orthotopic tumors derived from isolated mouse PDAC cell lines, which histologically resembled human hypoxic/necrotic PDAC phenotype including hypovascularization.

Similarly to HIF- $1 \alpha$, oncogenic K-ras plays a key role in the upregulation of glycolysis in PDACs through the transcriptional regulation of glucose transporters, monocarboxylate transporters, and glycolytic enzymes. Many glycolysis-related genes are overexpressed and are associated with poor prognosis of PDAC (e.g., LDHA, MCT4, GLUT1, HK2). An in silico analysis by McDonald and colleagues revealed the association of high CAIX expression with glycolytic phenotype (GLUT1, LDHA, MCT4, MCT1, PDK1) and poor prognosis of PDAC patients [75]. They also showed that CAIX is highly expressed in K-ras-driven KPCY (K-rasG12D/Pdx1-Cre/p53/RosaYFP) pancreatic tumors in genetically-engineered mouse models (GEMM). Silencing of CAIX in cell lines derived from KPCY GEMM tumors, implanted orthotopically, reduces tumor burden, and metastatic dissemination. Importantly, the administration of CAIX-specific inhibitor SLC-0111 to mice bearing PDAC xenografts reduced tumor growth compared with gemcitabine alone, while increasing their sensitivity to gemcitabine and significantly prolonging survival. Combined therapy also dramatically improved survival in orthotopic patient-derived xenograft (PDX) models where, after 3 months, $100 \%$ of cases were alive compared to around $70 \%$ in the gemcitabine-alone group, and none in the vehicle group. Furthermore, recent evidence indicates that CAIX enzymatic activity and associated extracellular acidosis play a key role not only in survival of cancer cells in hypoxia and their migration/invasion properties, but also in immunosurveillance. Antitumor immunity is attenuated by highly-acidic TME via several mechanisms [154-156]. For example, low $\mathrm{pH}$ inhibits infiltration and cytolytic activity of $\mathrm{CD}^{+} \mathrm{T}$ lymphocytes, but does not affect Treg cells which are immunosuppressive. Other mechanisms include inhibition of cytokine production, macrophage switch from M1 immune competent to M2 immunosuppressive phenotype, or resistance to immune check point immunotherapy [157].

Neutralization of tumor acidity, which is known to inhibit tumor growth or metastasis of some cancer types $[158,159]$, is also associated with increased CD8 ${ }^{+}$T-cell infiltration in immunocompetent mice [157]. A combination of neutralization of microenvironmental acidosis with anti-CTLA4 or anti-PD1 immune check point antibody greatly improved the anti-tumor response of these therapies. 
Pharmacological inhibition of tumor acidosis represents a promising tool to treat different cancers and overcome their metastatic spread. Orthotopic models of Panc02 human pancreatic cancer cells were insensitive to anti-PD-1 antibody as a monotherapy, but in combination with a specific CAIX inhibitor (DH348) or LDHA inhibitor (FX-11), were efficient in overcoming resistance to PD-1 blockade, while constraining metastasis [158]. The combination of SLC-0111 with anti-PD1 and anti-CTLA4 in mice bearing orthotopic breast tumors did not lead to visible tumor growth delay. However, histological evaluation showed increased necrosis, the extent of which was almost doubled in tumors treated with triple combination compared to tumors treated with SLC-0111 alone or an anti-PD1/anti-CTLA4 combination, respectively [160]. Moreover, triple combination treatment or SLC-0111, combined with either ICP antibody separately, achieved the most effective reduction of lung metastatic burden. Immune profiling of collected tumors revealed depletion of immune suppressive Tregs and Th17 cells, and a rise in cytotoxic CD8 ${ }^{+}$T-cells and Th1 cells, within the tumors treated with all three agents [160]. Thus, TME with decreased acidosis through CAIX inhibition creates a supportive environment for the effective activation of anti-tumor immunity, including efficiency of ICB immunotherapy. We assessed CA9 expression and the immune gene panel identified by D'Angelo et al. [145], differentiating patients with good and worse prognosis in a cohort of 183 PDAC samples from the TCGA database. In silico analysis revealed a negative correlation between CA9 and genes which are highly expressed in patients with a good outcome (Figure 9). Similarly, inverse correlation of CA9 with an immune activity signature was described for melanoma and basal-like breast cancer patients [160].

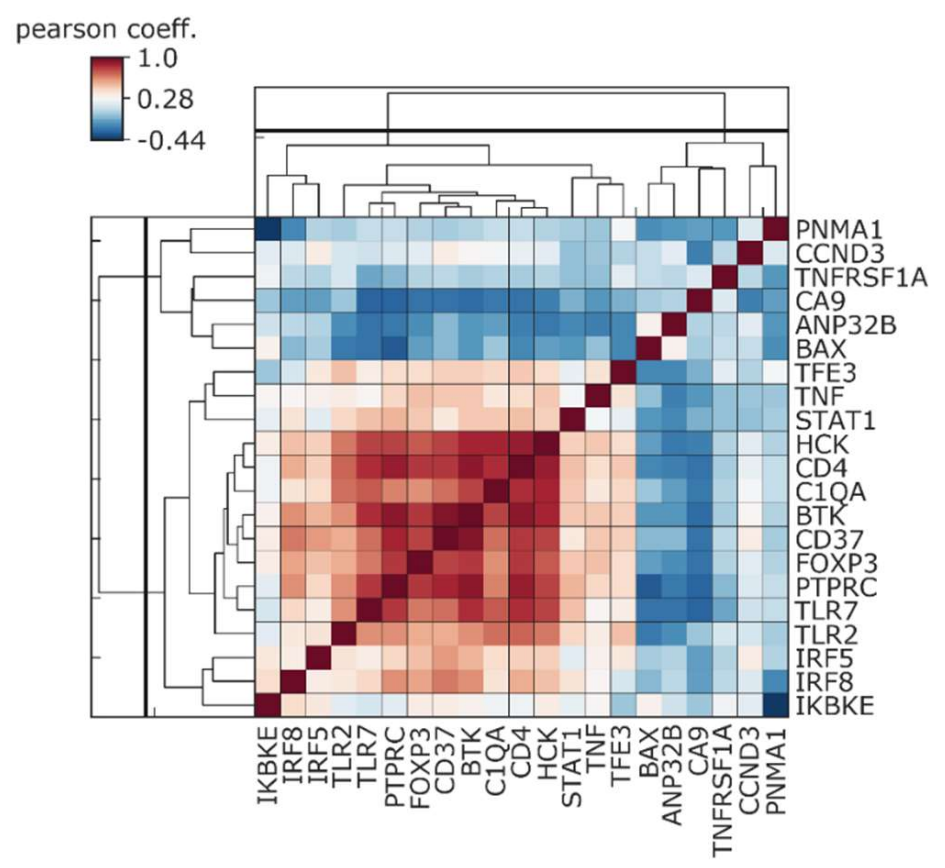

Figure 9. Negative correlation between CA9 and immune panel genes which are upregulated in samples with better prognosis. The analysis was performed with a cohort of 183 PDAC samples from TCGA (Xena).

Alternatively, inhibition of metastasizing through the targeting of acidosis using DH348, acetazolamide, FX-11, and bicarbonate was also able to effectively reduce metastasis arising after tail vein injection in mice [158]. Additionally, specific anti-CAIX antibodies prevented lung metastasis formation of intravenously injected HT1080 cells in mice. Moreover, these antibodies also abrogated the capability of cancer cells to invade through the chorioallantoic membranes of quail embryos [16]. 


\section{Clinical Trials Targeting CAIX-Related Molecular Pathways}

The prevention, diagnosis, and treatment of pancreatic cancer are extremely difficult as symptoms are non-specific or even lacking, and effective screening tools for detection are not in place. Once diagnosed, the disease has usually advanced, making fewer than $20 \%$ of patients fit candidates for surgical resection [161]. Therapeutic options are limited, as most pancreatic cancers-owing to their complex genetic and metabolic nature and the ongoing crosstalk between the cells of the TME-have a poor response to chemotherapy. This naturally translates to an extremely dismal mortality-incidence ratio of $94 \%$ [32]. With 2671 currently registered clinical trials at https://clinicaltrials.gov, the devastating fatality of pancreatic cancer undoubtedly drives further development of effective therapeutic protocols. Here, we summarize completed, ongoing, and recruiting clinical trials in pancreatic cancer targeting CAIX-related molecular pathways, while still relying on treatment "backbones" most frequently consisting of gemcitabine, nab-paclitaxel, or the combination chemotherapy regimen FOLFIRINOX (oxaliplatin, irinotecan, fluorouracil, and leucovorin) now considered the standard first-line treatment for patients diagnosed with advanced stage pancreatic cancer, as it provides a 4.3 month increase in OS when compared to gemcitabine alone [162].

\subsection{CAIX}

SLC-0111-mediated CAIX inhibition has proven to be effective in patient-derived 2D and 3D PDAC cell cultures [64,65], followed by an SLC-0111 safety study (NCT02215850) in advanced solid tumors. Currently, a Phase 1/2 clinical trial (NCT03450018) uses the selective, small molecule inhibitor SLC-0111 in CAIX-positive patients diagnosed with metastatic PDAC. The study completion is estimated in 2022. CAIX is actively involved in the metastatic cascade and migration [12], localizes at focal adhesion sites [23], and within invadopodia [16]. A currently-recruiting Phase 1 clinical trial (NCT03199586) aims to target the migratory pathway via NP-G2-044. This drug targets and binds fascin and, hence, obstructs the fascin/actin interaction. By preventing filopodia formation and cytoskeletal reorganization, NP-G2-044 impairs cancer cell migration.

\subsection{Angiogenesis}

Angiogenesis in solid tumors is regulated by hypoxia and acidic $\mathrm{pH}$. VEGF expression is under the regulation of HIF [163], while CAIX expression supports angiogenesis by contributing to extracellular acidosis [21]. In line with this, the inhibition of CAIX was shown to significantly enhance anti-VEGF therapy in a preclinical setting [164]. Patients with increased tissue and plasma CAIX values are unlikely to profit from sunitinib-based anti-angiogenic therapy [165]. Combination therapy of the recombinant humanized anti-VEGF monoclonal antibody bevacizumab and gemcitabine in a Phase 2 clinical trial yielded a partial response for $21 \%$ of patients and disease stabilization in $46 \%$ of patients diagnosed with advanced pancreatic cancer [166], with a significantly decreased reciprocal of doubling time [167] reported in another study (NCT00460174). The combination of bevacizumab, capecitabine, and gemcitabine (NCT00100815) results in a mean progression free survival (PFS) of 5.7 months and a mean OS of 9.8 months, but a regimen consisting of bevacizumab, capecitabine, and radiation therapy still seems to be more efficient with a reported median PFS of 8.6 months and a median survival rate of 11.9 months (NCT00114179; [168]).

While targeting VEGF in pancreatic cancer might not result in the anticipated outcome, preventing neo-vascularization by anti-angiogenic therapy still remains a promising way of preventing tumor growth. A new antiangiogenic drug combination TL-118 was reported to be extremely effective in a case report study [169]. When re-administered, the drug efficiently decreased elevated tumor marker levels observed after TL-118 treatment termination. The studied pancreatic cancer patient, treated with standard chemotherapy and TL-118, was still considered progression-free 16 months post-diagnosis. Two Phase 2 clinical trials (NCT01509911, NCT01659502) studying TL-118 in pancreatic cancer followed. 
Clinical studies have also examined the effect of multi-targeted tyrosine kinase inhibitors, e.g., sunitinib malate (NCT00397787, NCT00462553, NCT00967603), axitinib (NCT00471146), masitinib (NCT00789633), and vatalanib (NCT00185588). Sunitinib [170] and axitinib [171] seem to have minimal activity in advanced pancreatic adenocarcinoma. A clinical trial studying the effects of masitinib in combination with gemcitabine divided patients into two sub-groups based on acyl-CoA oxidase-1 (ACOX1) overexpression or baseline pain intensity threshold evaluation. While patients in the latter study group achieved a mean OS of 8 months, masitinib treatment resulted in significantly increased OS in the ACOX1 group (median 11.7 months; [172]). The combined Phase 1/2 clinical trial (NCT00185588) examines the drug combination of vatalanib and gemcitabine for patients with unresectable pancreatic cancer. After successful optimal safe and tolerable dose determination, the antitumor efficacy of this regimen is to be established.

\subsection{Epidermal Growth Factor Receptor (EGFR) Inhibition}

EGFR activates the MAPK/ERK and PI3K/AKT pathways, both involved in the transcriptional activation of CA9 expression [61,62]. Two Phase 1 clinical trials (NCT04045496) are yet to investigate the MAPK inhibitor JAB-3312 in advanced solid tumors, including pancreatic cancer. The MEK kinase inhibitor AZD6244 was evaluated in comparison to capecitabine in an already-completed Phase 2 clinical trial (NCT00372944) designed for patients suffering from pancreatic cancer for whom gemcitabine therapy has failed. The anti-EGFR monoclonal antibody cetuximab was investigated in numerous clinical trials, including a Phase 2 clinical trial (NCT00225784) where the drug was administered in combination with gemcitabine and radiotherapy. Out of 33 participants, 10 partial responses were achieved, the disease was stabilized in 20 patients and, in 3 cases, the disease progressed. However, cetuximab-mediated EGFR inhibition does not seem to be beneficial when compared to cetuximab-free study arms (NCT00042939, NCT00075686, NCT00536614). The consensus among clinical studies and literature is that cetuximab does not increase response nor survival in EGFR-positive patients [173] and does not yield an improved outcome compared to gemcitabine [174]. The EGFR inhibitor nimotuzumab was investigated in a Phase 2/3 clinical trial (NCT00561990), where the combination of gemcitabine and nimotuzumab was shown to be well-tolerated and significantly improved the 1-year OS, with a significantly better OS (11.6 versus 5.6 months, $p=0.03$ ) achieved in patients harboring the K-ras mutation [175]. The drug erlotinib, responsible for inhibiting EGFR phosphorylation and subsequent signalization, was investigated in a Phase 2 clinical study (NCT00810719) in combination with gemcitabine for treating patients with metastatic/recurrent pancreatic cancer, but showed no signs of efficacy. Another clinical trial (NCT01608841) analyzing the same drug combination showed gemcitabine + erlotinib to have a superior efficacy compared to gemcitabine alone. Disease control (including complete response, partial response, and stable disease) in metastatic pancreatic cancer patients was significantly better ( $85 \%$ vs. $33 \% ; p=0.001)$ in patients harboring the EGFR mutation [176]. A Phase 3 clinical trial (NCT00040183) with 569 patients enrolled also reported results in favor of the erlotinib/gemcitabine treatment, indicating a longer 1-year survival when erlotinib was administered $(23 \%$ v $17 \% ; p=0.023)$. The achieved OS was also statistically significant but still extremely modest (6.24 months vs. 5.91 months), considering that patients in the erlotinib arm suffered from more grade 1 and 2 adverse events [177].

The combination of bevacizumab and erlotinib was shown to be inefficient for patients resistant to gemcitabine (NCT00365144, NCT00366457, NCT00925769), as the overall 6-month survival rate was only 22\% [178]. A clinical trial (NCT00091026) also compared the effects of bevacizumab and gemcitabine with either cetuximab or erlotinib, but no difference between mean PFS and OS was observed between study arms. Similarly, the difference in 2-year OS and disease-free survival between cetuximab and bevacizumab administered as a complement to gemcitabine, capecitabine, and radiation is statistically insignificant among study arms (NCT00305877). 


\section{4. $A K T$}

Inhibition of the AKT signaling pathway can clinically be achieved by MK-2206, which inhibits the kinase in an ATP-noncompetitive manner, and RX-0201, an Akt1 antisense oligonucleotide. A preclinical study evaluating the combination of the CDK inhibitor dinaciclib and MK-2206 showed great promise in pancreatic cancer therapy, as treatment achieved some complete responses and blocked tumor growth in all of the patient-derived xenograft models [179]. Based on these results, a clinical trial (NCT01783171) was initiated. However, MK-2206 administered in combination with selumetinib showed no advantage for patients for whom gemcitabine-based therapy had failed (NCT01658943). A Phase 2 clinical trial (NCT01028495) using RX-0201 + gemcitabine for patients with metastatic disease was initiated based on a preclinical study on pancreatic cancer cell lines and xenograft mouse models, which showed the therapeutic potential of the novel Akt1 antisense oligonucleotide [180].

\subsection{Hypoxia-Activated Prodrugs}

Hypoxic regions of solid tumors frequently account for treatment failure and, hence, are an attractive target for novel drug design and therapy. TH-302 (evofosfamide), an investigational hypoxia-activated prodrug, is reduced by one-electron reductive enzymes (e.g., NAPDH cytochrome P450) to form a radical anion. Under hypoxic conditions, it is further fragmented, generating bromo-isophosphoramide mustard (Br-IPM). Hypoxia-dependent TH-302 activation results in a cytotoxic agent mediating DNA crosslinking and cell cycle arrest [181]. Several clinical trials have evaluated the effects of TH-302 in combination with gemcitabine and/or nab-paclitaxel. In a preclinical study [182], the combination of gemcitabine + nab-paclitaxel + TH-302 has shown superior efficacy in human tumor xenograft models of pancreatic cancer. These promising results translated into a Phase I clinical trial (NCT02047500), which has unfortunately been terminated following the company's decision to discontinue the clinical development of evofosfamide. In a conducted Phase 2 study (NCT01144455), gemcitabine + TH-302 yielded a significantly longer PFS and an improved tumor response [183] compared to gemcitabine alone. The drug combination was further investigated in a Phase 3 clinical trial (NCT01746979).

\subsection{Hedgehog Signaling}

The hypoxia-triggered SHH pathway [85] is aberrantly activated in a malignant pancreas [184]. Since HH signaling inhibition enhanced gemcitabine delivery in mice [185], targeting the hedgehog pathway in pancreatic cancer became very promising. Vismodegib (GDC-0449), a selective HH pathway inhibitor which binds to the SMO receptor, repeatedly did not show improved PFS and OS in Phase 1/2 clinical trials (NCT01064622, NCT01088815, NCT01195415) and was not shown to be superior to gemcitabine alone in the treatment of metastatic pancreatic cancer. LDE-225, an SMO antagonist, was also shown to inhibit EMT [186] and, combined with gemcitabine and nab-paclitaxel, was proven to be well tolerated (NCT02358161) with promising efficacy [187]. An additional SMO inhibitor compound, IPI-926, has also been tested in several Phase 1/2 clinical trials combined with gemcitabine (NCT01130142; [188]).

\subsection{Mammalian Target of Rapamycin (mTOR)}

The mammalian target of rapamycin (mTOR) is an upstream regulator of HIF-1 $\alpha$ [189], as well as of a number of other downstream target genes involved in angiogenesis, cell growth and proliferation, bioenergetics, and survival [190]. As such, it is another rational target in the treatment of pancreatic cancer [191]. CAIX knockdown was shown to improve the therapeutic efficacy of rapamycin preclinically [192], justifying clinical evaluation of such dual targeting. Drugs targeting the mTOR pathway that are currently under clinical investigation for the treatment of pancreatic cancer include sirolimus (rapamycin) and its analogue everolimus. A Phase 1/2 clinical study (NCT03662412) aims to investigate the effect of sirolimus monotherapy and is currently recruiting participants, with an 
estimated study completion in 2023. A Phase 3 clinical trial (NCT00510068) evaluated the efficacy of everolimus in pNET patients, with an encouraging median PFS of 11.04 months for patients treated with everolimus compared to a median PFS of 4.60 for patients treated with a placebo. Despite being statistically insignificant, the OS in this study was also promising-everolimus treatment yielded a median OS of 44.02 months (max. 51.75 months), while placebo treatment resulted in an OS median of 37.68 months. The safe and well-tolerated anti-diabetic drug metformin was shown to efficiently suppress mTOR activation [193] in pancreatic cancer [194], as well as other cancers [195]. In a clinical setting, the combination therapy consisting of gemcitabine, erlotinib, and metformin had no effect on the outcome of patients suffering from advanced pancreatic cancer when compared to the placebo (NCT01210911; [196]). In patients diagnosed with diabetes mellitus prior to pancreatic cancer diagnosis, metformin use translated into an improved outcome in patients suffering from non-metastatic disease, suggesting an improved chemotherapy response [197].

\subsection{Immunotherapy}

Aiming to boost the function of the immune system and elicit an anti-tumor response via T-cell activation, a number of agents targeting immune checkpoint inhibitors of the PD-1/PDL-1 pathway are already approved by food and drug administration (FDA) for different cancer types [198,199]. Immune activity is hindered by low $\mathrm{pH}[157,200]$ and lactate accumulation [201], providing a rationale for combining CAIX inhibition with immune checkpoint blockade-based therapy in a clinical setting. In support of this, Chafe et al. showed that by reducing pHe acidification, SLC-0111 enhances T-cell killing and aids anti-PD1 therapy in vitro [160]. Most clinical trials at various stages targeting PD-1 in pancreatic cancer are currently recruiting or ongoing (Table 1), including a Phase 1 clinical trial (NCT04181645) with an estimated termination date in 2022 evaluating the safety and efficacy of the combination treatment of SHR-1210 (a humanized anti-PD1 monoclonal antibody), nab-paclitaxel, and gemcitabine in a cohort of metastatic PDAC patients. A Phase 3 clinical trial of 830 participants (NCT03983057) is currently investigating antibody-mediated PD1 inhibition together with chemotherapy in relation to response rate, OS, and PFS.

Table 1. Clinical trials for pancreatic cancer targeting molecular pathways with relationship to CAIX.

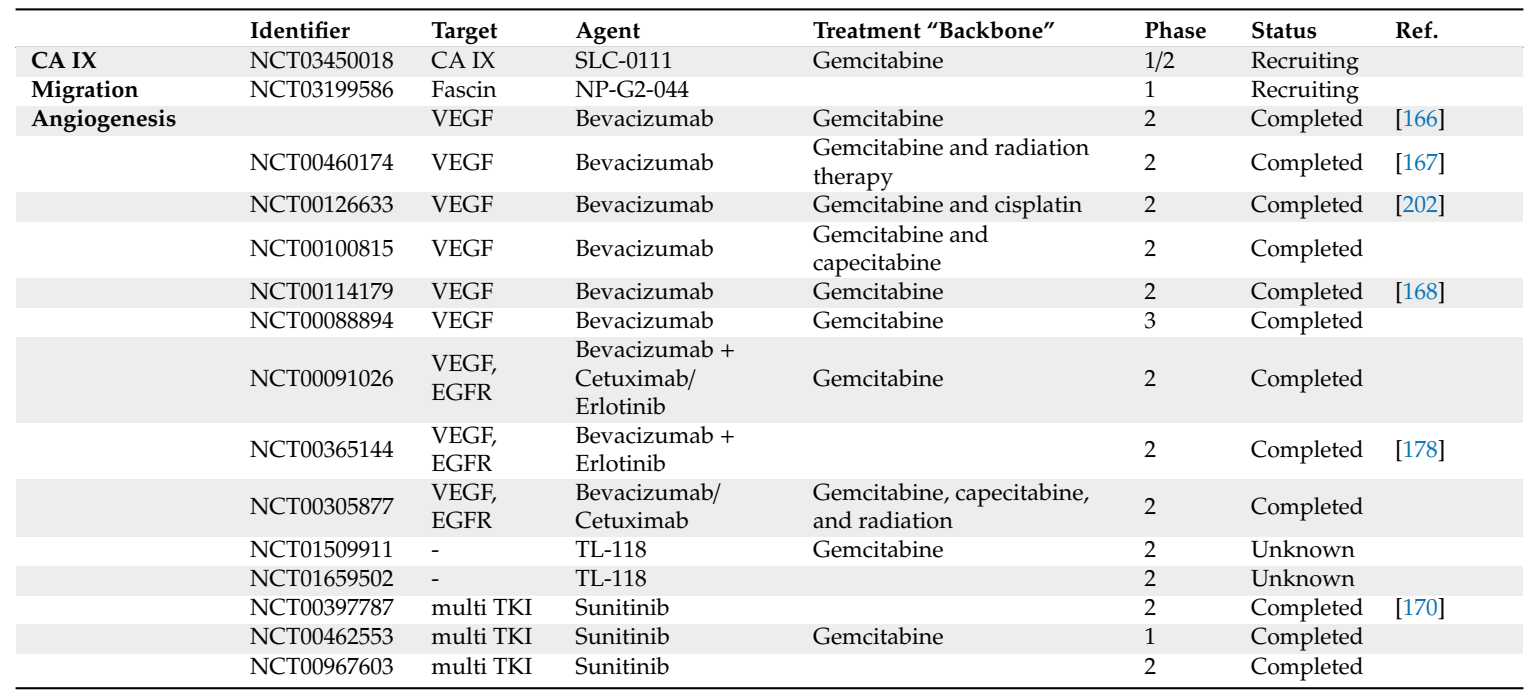


Table 1. Cont.

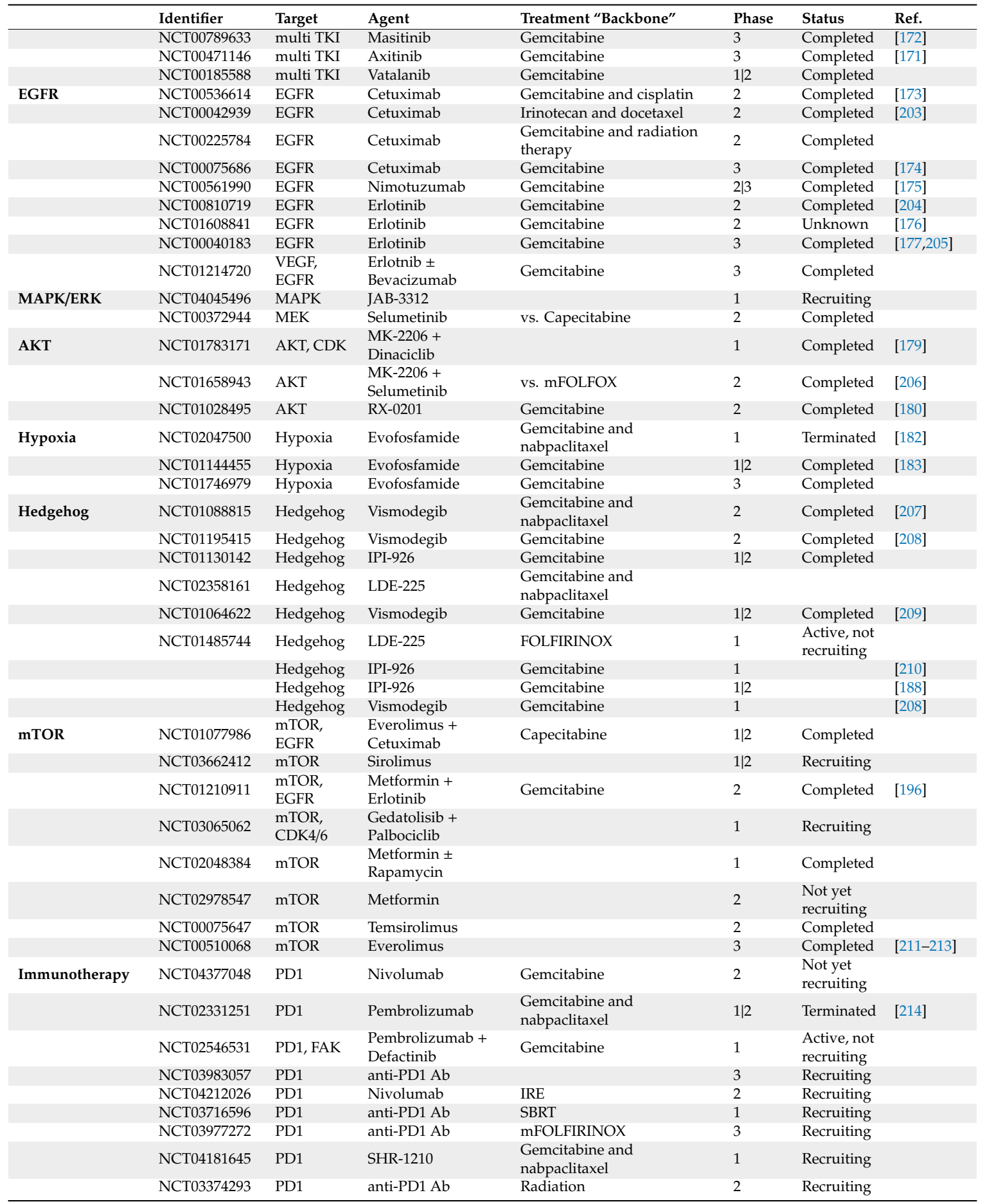

\section{Conclusions and Future Directions}

Currently, the most common diagnostic tools to detect PDAC are imaging techniques including computed tomography (CT), magnetic resonance imaging (MRI), positron emission tomography (PET), and endoscopic ultrasound (EUS), correlated with blood levels of CA19-9 and amylase. Unfortunately, they are unable to detect early lesions and are mainly used for disease staging.

Features of the pancreatic cancer TME such as desmoplasia, hypovascularization, hypoxia, and acidosis represent a physical-ecological barrier implicated in resistance to chemotherapy, radiotherapy, and immunotherapy. As we summarize in this review, even the early stages of 
pancreatic carcinogenesis are associated with hypoxia response, acidosis, and CAIX expression, which are exploitable diagnostic targets. Extensive data indicate that CAIX is a valuable diagnostic marker and therapy target. Detection of acidic TME through $\mathrm{pH}$-sensitive probes or specific anti-CAIX antibodies, conjugated with agents detectable by routine radiomic imaging used in pancreatic cancer diagnostics, could represent a promising tool for identification of early pre-cancerous lesions. Indeed, an ${ }^{131}$ I-cG250 conjugated antibody-recognizing CAIX protein was successfully used in clinics to detect CAIX-positive primary tumor and disseminated metastasis [151]. Animal models show that CAIX can be a useful target for molecular imaging based on monoclonal antibodies or inhibitors tagged with various radionuclides [215-217].

There is an ongoing effort to identify parameters and novel predictive markers which would help to tailor therapy for pancreatic cancer patients as well as to predict treatment outcome. Recent studies investigated the possibility of predicting the response to neoadjuvant radiochemotherapy according to microenvironmental factors (hypoxia, tumor vascularization, stromal activation) and evaluated hypoxia as a relevant tool for patient stratification. Studies have used pre-operative pimonidazole administration correlated with post-operative CAIX staining as a means to determine hypoxia extent (NCT01989000, NCT03718650, NCT01248637). One of the aims of these studies is to assess if features of non-invasive radiomic imaging prior to surgery correspond with intratumor hypoxia determined in the specimen after surgery by immunohistochemical staining of CAIX, GLUT1, or HIF- $1 \alpha$.

Since hypoxia and acidosis strongly influence anti-tumor treatment efficacy, targeting hypoxic/acidic TME through CAIX protein can enhance the efficiency of conventional therapies and improve the infiltration of immunocompetent cells or overcome immunotherapy resistance. Increased efficiency of combinatorial treatment consisting of CAIX inhibition and clinically-used therapies or those under clinical trials in PDAC patients was shown in different preclinical pancreatic or other models. This includes the knockdown/inhibition of CAIX combined with the chemotherapy drugs gemcitabine or paclitaxel, mTOR inhibitors (rapamycin), inhibitor of HIF- $1 \alpha$-targeting APE1/Ref-1 (APX3330), inhibition of angiogenesis (bevacizumab), or in combination with immune check point immunotherapy $[65,75,158,160,164,192,218]$. Furthermore, data from a Phase 3 clinical trial (ARISER) using a monoclonal antibody against CAIX, cG250, where the mechanism of action is based on immune response (antibody-dependent cellular cytotoxicity), revealed a prolonged disease-free survival up to 22 months in a patient cohort with high CAIX [219].

In conclusion, based on vast evidence from literature and clinical trials, we believe that therapies combining clinically-administered therapeutic regimens with CAIX targeting could improve the efficacy of anti-tumor response in patients with pancreatic ductal adenocarcinoma.

Supplementary Materials: The following are available online at http://www.mdpi.com/2072-6694/12/8/2005/s1. The detailed description of methods used in in silico analysis and immunohistochemistry is provided in Supplementary data file which is available online.

Author Contributions: E.S. designed the concept, wrote and revised the article. S.S. performed clinical trials analysis, wrote and revised the manuscript. L.C. and M.T. preformed in silico analysis, wrote, and revised the paper. P.M. provided patient samples and revised the manuscript. L.L. performed immunohistochemistry. V.G. evaluated clinicopathological parameters of tissue sections. J.K. performed visualization, and critically read the manuscript. All authors have read and agreed to the published version of the manuscript.

Funding: This research was funded by the Research and Development Support Agency APVV-14-0816, Slovak Scientific Grant Agency VEGA 2/0105/19, VEGA 2/0064/18, VEGA 2/0076/20, H2020 project VISION grant agreement No 857381, Slovak Academic Information Agency (SAIA)_Action Austria-Slovakia.

Acknowledgments: We are grateful to Silvia Pastorekova for the critical reading of the manuscript, valuable comments and discussion.

Conflicts of Interest: The authors declare no conflict of interest. 


\section{Abbreviations}

\begin{tabular}{|c|c|}
\hline CEST & Chemical exchange saturation transfer \\
\hline ACOX1 & Acyl-coA oxidase-1 \\
\hline $\mathrm{AP}$ & Activating protein \\
\hline APE1/Ref-1 & AP (apurinic/apyrimidinic) endonuclease1/redox effector factor 1 \\
\hline ARG2 & Arginase II \\
\hline ATDC & Ataxia-telangiectasia group D complementing gene \\
\hline $\mathrm{CA}$ & Carbonic anhydrase \\
\hline CAF & Cancer associated fibroblast \\
\hline CD & Cluster of differentiation \\
\hline COX-2 & Cyclooxygenase- 2 \\
\hline $\mathrm{CT}$ & Computed tomography \\
\hline CTLA4 & Cytotoxic T-lymphocyte antigen 4 \\
\hline CTPS1 & Cytidine 5'-triphosphate synthetase \\
\hline DAMP & Damage-associated molecular pattern \\
\hline DFS & Disease free survival \\
\hline DNMT3a & DNA methyltransferase $3 a$ \\
\hline DVL-2 & Dishevelled 2 \\
\hline EGFR & Epidermal growth factor Receptor \\
\hline EMT & Epithelial-mesenchymal transition \\
\hline EpCAM & Epithelial cell adhesion molecule \\
\hline ERK & Extracellular signal-regulated kinase \\
\hline FZD1 & Frizzled-1 \\
\hline GEMM & Genetically engineered mouse model \\
\hline GLI1 & Glioma-associated oncogene homolog 1 (zinc finger protein) \\
\hline GLUT & Glucose transporter \\
\hline GTEx & Genotype-tissue expression \\
\hline Her-2 & Human epidermal growth factor receptor 2 \\
\hline $\mathrm{HH}$ & Hedgehog \\
\hline HIF & Hypoxia-inducible factor \\
\hline HK2 & Hexokinase 2 \\
\hline HRE & Hypoxia-responsive element \\
\hline IGF2BP3 & Insulin-like growth factor 2 mRNA-binding protein 3 \\
\hline IL & Interleukin \\
\hline IPMN & Intraductal papillary mucinous neoplasm \\
\hline IQGAP1 & IQ motif containing GTPase activating protein 1 \\
\hline K-ras & Kirsten rat sarcoma viral oncogene homolog \\
\hline KIF14 & Kinesin family member \\
\hline LDHA & Lactate dehydrogenase A \\
\hline MAPK & Mitogen-activated protein kinase \\
\hline $\mathrm{MCN}$ & Mucinous cystic neoplasm \\
\hline MCT & Monocarboxylate transporters \\
\hline MEK & Mitogen-activated protein kinase \\
\hline MRI & Magnetic resonance imaging \\
\hline mTOR & Mammalian target of rapamycin \\
\hline MUC & Mucin \\
\hline MVD & Microvessel density \\
\hline MVI & Microvessel integrity \\
\hline NBCe1 & Electrogenic sodium/bicarbonate cotransporter 1 \\
\hline NBCn1 & Electroneutral sodium/bicarbonate cotransporter 1 \\
\hline NF- $k B$ & Nuclear factor kappa-light-chain-enhancer of activated B cells \\
\hline NHE1 & Sodium/hydrogen exchanger 1 \\
\hline OS & Overall survival \\
\hline PanIN & Pancreatic intraepithelial neoplasia \\
\hline PD1 & Programmed cell death protein 1 \\
\hline
\end{tabular}




\begin{tabular}{|c|c|}
\hline PDAC & Pancreatic ductal adenocarcinoma \\
\hline PDK1 & Pyruvate dehydrogenase kinase 1 \\
\hline PDL-1 & Programmed death-ligand 1 \\
\hline PDX & Patient-derived xenograft \\
\hline PET & Positron emission tomography \\
\hline PFS & Progression-free survival \\
\hline PG & Proteoglycan-like domain \\
\hline PGE2 & Prostaglandin E2 \\
\hline pHLIP peptide & $\mathrm{pH}$ (low) insertion peptide \\
\hline PI3K & Phosphatidyl inositol 3-kinase \\
\hline PKM2 & Pyruvate kinase muscle isozyme \\
\hline PPBP & Pro-platelet basic protein \\
\hline PSCA & Prostate stem cell antigen \\
\hline qRT-PCR & Real-time quantitative reverse transcription PCR \\
\hline RTK & Receptor tyrosine kinase \\
\hline SERPINB5 & Serpin family B member 5 \\
\hline $\mathrm{SHH}$ & Sonic Hedgehog \\
\hline SLC & Solute carrier family membrane transport protein \\
\hline $\mathrm{SMO}$ & Smoothened \\
\hline SP1 & Specificity protein 1 \\
\hline TCGA & The cancer genome atlas \\
\hline TET & Ten-eleven translocation enzymes \\
\hline $\mathrm{TF}$ & Transcription factors \\
\hline TGF- $\beta$ & Transforming growth factor $\beta$ \\
\hline Th cells & T-helper cells \\
\hline TIC & Tumor initiating cell \\
\hline TKT & Transketolase \\
\hline TLR & Toll-like receptor \\
\hline TME & Tumor microenvironment \\
\hline TMPRSS3 & Transmembrane serine protease 3 \\
\hline TNF- $\alpha$ & Tumor necrosis factor $\alpha$ \\
\hline TPM2 & $\beta$-tropomyosin \\
\hline Tregs & $\mathrm{T}$ regulatory cells \\
\hline TSS & Transcription start site \\
\hline uPAR & Urokinase-type plasminogen activator receptor \\
\hline VEGF & Vascular endothelial growth factor \\
\hline$\alpha-S M A$ & $\alpha$-smooth muscle actin \\
\hline
\end{tabular}

\section{References}

1. Parkkila, A.K.; Parkkila, S.; Serlo, W.; Reunanen, M.; Vierjoki, T.; Rajaniemi, H. A competitive dual-label time-resolved immunofluorometric assay for simultaneous detection of carbonic anhydrase I and II in cerebrospinal fluid. Clin. Chim. Acta 1994, 230, 81-89. [CrossRef]

2. Parkkila, A.K.; Scarim, A.L.; Parkkila, S.; Waheed, A.; Corbett, J.A.; Sly, W.S. Expression of carbonic anhydrase $\mathrm{V}$ in pancreatic beta cells suggests role for mitochondrial carbonic anhydrase in insulin secretion. J. Biol. Chem. 1998, 273, 24620-24623. [CrossRef]

3. Nishimori, I.; FujikawaAdachi, K.; Onishi, S.; Hollingsworth, M.A. Carbonic anhydrase in human pancreas: Hypotheses for the pathophysiological roles of CA isozymes. Ann. N. Y. Acad. Sci. 1999, 880, 5-16. [CrossRef] [PubMed]

4. Kivela, A.J.; Parkkila, S.; Saarnio, J.; Karttunen, T.J.; Kivela, J.; Parkkila, A.K.; Pastorekova, S.; Pastorek, J.; Waheed, A.; Sly, W.S.; et al. Expression of transmembrane carbonic anhydrase isoenzymes IX and XII in normal human pancreas and pancreatic tumours. Histochem. Cell Biol. 2000, 114, 197-204. [CrossRef] [PubMed] 
5. Inada, A.; Nienaber, C.; Fonseca, S.; Bonner-Weir, S. Timing and expression pattern of carbonic anhydrase II in pancreas. Dev. Dyn. 2006, 235, 1571-1577. [CrossRef] [PubMed]

6. Pastorekova, S.; Parkkila, S.; Parkkila, A.K.; Opavsky, R.; Zelnik, V.; Saarnio, J.; Pastorek, J. Carbonic anhydrase IX, MN/CA IX: Analysis of stomach complementary DNA sequence and expression in human and rat alimentary tracts. Gastroenterology 1997, 112, 398-408. [CrossRef] [PubMed]

7. Nishimori, I.; Onishi, S. Carbonic anhydrase isozymes in the human pancreas. Dig. Liver Dis. 2001, 33, 68-74. [CrossRef]

8. Mboge, M.Y.; Mahon, B.P.; McKenna, R.; Frost, S.C. Carbonic Anhydrases: Role in pH Control and Cancer. Metabolites 2018, 8, 19. [CrossRef]

9. Opavsky, R.; Pastorekova, S.; Zelnik, V.; Gibadulinova, A.; Stanbridge, E.J.; Zavada, J.; Kettmann, R.; Pastorek, J. Human MN/CA9 gene, a novel member of the carbonic anhydrase family: Structure and exon to protein domain relationships. Genomics 1996, 33, 480-487. [CrossRef]

10. Svastova, E.; Hulikova, A.; Rafajova, M.; Zat'ovicova, M.; Gibadulinova, A.; Casini, A.; Cecchi, A.; Scozzafava, A.; Supuran, C.T.; Pastorek, J.; et al. Hypoxia activates the capacity of tumor-associated carbonic anhydrase IX to acidify extracellular pH. FEBS Lett. 2004, 577, 439-445. [CrossRef]

11. Swietach, P.; Patiar, S.; Supuran, C.T.; Harris, A.L.; Vaughan-Jones, R.D. The role of carbonic anhydrase 9 in regulating extracellular and intracellular ph in three-dimensional tumor cell growths. J. Biol. Chem. 2009, 284, 20299-20310. [CrossRef] [PubMed]

12. Svastova, E.; Witarski, W.; Csaderova, L.; Kosik, I.; Skvarkova, L.; Hulikova, A.; Zatovicova, M.; Barathova, M.; Kopacek, J.; Pastorek, J.; et al. Carbonic anhydrase IX interacts with bicarbonate transporters in lamellipodia and increases cell migration via its catalytic domain. J. Biol. Chem. 2012, 287,3392-3402. [CrossRef] [PubMed]

13. Orlowski, A.; De Giusti, V.C.; Morgan, P.E.; Aiello, E.A.; Alvarez, B.V. Binding of carbonic anhydrase IX to extracellular loop 4 of the NBCe1 Na+/HCO3- cotransporter enhances NBCe1-mediated HCO3- influx in the rat heart. Am. J. Physiol. Cell Physiol. 2012, 303, C69-C80. [CrossRef] [PubMed]

14. Ames, S.; Pastorekova, S.; Becker, H.M. The proteoglycan-like domain of carbonic anhydrase IX mediates non-catalytic facilitation of lactate transport in cancer cells. Oncotarget 2018, 9, 27940-27957. [CrossRef] [PubMed]

15. Goldman, M.J.; Craft, B.; Hastie, M.; Repecka, K.; McDade, F.; Kamath, A.; Banerjee, A.; Luo, Y.; Rogers, D.; Brooks, A.N.; et al. Visualizing and interpreting cancer genomics data via the Xena platform. Nat. Biotechnol. 2020, 38, 675-678. [CrossRef]

16. Debreova, M.; Csaderova, L.; Burikova, M.; Lukacikova, L.; Kajanova, I.; Sedlakova, O.; Kery, M.; Kopacek, J.; Zatovicova, M.; Bizik, J.; et al. CAIX Regulates Invadopodia Formation through Both a pH-Dependent Mechanism and Interplay with Actin Regulatory Proteins. Int. J. Mol. Sci. 2019, 20, 2745. [CrossRef]

17. Swayampakula, M.; McDonald, P.C.; Vallejo, M.; Coyaud, E.; Chafe, S.C.; Westerback, A.; Venkateswaran, G.; Shankar, J.; Gao, G.; Laurent, E.M.N.; et al. The interactome of metabolic enzyme carbonic anhydrase IX reveals novel roles in tumor cell migration and invadopodia/MMP14-mediated invasion. Oncogene 2017, 36, 6244-6261. [CrossRef]

18. Svastova, E.; Zilka, N.; Zat'ovicova, M.; Gibadulinova, A.; Ciampor, F.; Pastorek, J.; Pastorekova, S. Carbonic anhydrase IX reduces E-cadherin-mediated adhesion of MDCK cells via interaction with beta-catenin. Exp. Cell Res. 2003, 290, 332-345. [CrossRef]

19. Zatovicova, M.; Sedlakova, O.; Svastova, E.; Ohradanova, A.; Ciampor, F.; Arribas, J.; Pastorek, J.; Pastorekova, S. Ectodomain shedding of the hypoxia-induced carbonic anhydrase IX is a metalloprotease-dependent process regulated by TACE/ADAM17. Br. J. Cancer 2005, 93, 1267-1276. [CrossRef]

20. Pastorek, J.; Pastorekova, S. Hypoxia-induced carbonic anhydrase IX as a target for cancer therapy: From biology to clinical use. Semin. Cancer Biol. 2015, 31, 52-64. [CrossRef]

21. Pastorekova, S.; Gillies, R.J. The role of carbonic anhydrase IX in cancer development: Links to hypoxia, acidosis, and beyond. Cancer Metastasis Rev. 2019, 38, 65-77. [CrossRef] [PubMed]

22. Zavadova, Z.; Zavada, J. Carbonic anhydrase IX (CA IX) mediates tumor cell interactions with microenvironment. Oncol. Rep. 2005, 13, 977-982. [CrossRef] [PubMed]

23. Csaderova, L.; Debreova, M.; Radvak, P.; Stano, M.; Vrestiakova, M.; Kopacek, J.; Pastorekova, S.; Svastova, E. The effect of carbonic anhydrase IX on focal contacts during cell spreading and migration. Front. Physiol. 2013, 4, 271. [CrossRef] [PubMed] 
24. Wykoff, C.C.; Beasley, N.J.; Watson, P.H.; Turner, K.J.; Pastorek, J.; Sibtain, A.; Wilson, G.D.; Turley, H.; Talks, K.L.; Maxwell, P.H.; et al. Hypoxia-inducible expression of tumor-associated carbonic anhydrases. Cancer Res. 2000, 60, 7075-7083.

25. Couvelard, A.; O’Toole, D.; Leek, R.; Turley, H.; Sauvanet, A.; Degott, C.; Ruszniewski, P.; Belghiti, J.; Harris, A.L.; Gatter, K.; et al. Expression of hypoxia-inducible factors is correlated with the presence of a fibrotic focus and angiogenesis in pancreatic ductal adenocarcinomas. Histopathology 2005, 46, 668-676. [CrossRef]

26. Li, Y.; Dong, M.; Sheng, W.; Huang, L. Roles of Carbonic Anhydrase IX in Development of Pancreatic Cancer. Pathol. Oncol. Res. 2016, 22, 277-286. [CrossRef]

27. Yang, L.; Yang, Z.; Li, D.; Liu, Z.; Zou, Q.; Yuan, Y.; Xu, H. Overexpression of FZD1 and CAIX are Associated with Invasion, Metastasis, and Poor-Prognosis of the Pancreatic Ductal Adenocarcinoma. Pathol. Oncol. Res. 2018, 24, 899-906. [CrossRef]

28. Knudsen, E.S.; Balaji, U.; Freinkman, E.; McCue, P.; Witkiewicz, A.K. Unique metabolic features of pancreatic cancer stroma: Relevance to the tumor compartment, prognosis, and invasive potential. Oncotarget 2016, 7, 78396-78411. [CrossRef]

29. Pore, N.; Jalla, S.; Liu, Z.; Higgs, B.; Sorio, C.; Scarpa, A.; Hollingsworth, R.; Tice, D.A.; Michelotti, E. In Vivo Loss of Function Screening Reveals Carbonic Anhydrase IX as a Key Modulator of Tumor Initiating Potential in Primary Pancreatic Tumors. Neoplasia 2015, 17, 473-480. [CrossRef]

30. Cancer Stat Facts: Pancreatic Cancer. Available online: https://seer.cancer.gov/statfacts/html/pancreas.html (accessed on 6 June 2020).

31. Howlader, N.; Noone, A.M.; Krapcho, M.; Miller, D.; Bishop, K.; Kosary, C.L.; Yu, M.; Ruhl, J.; Tatalovich, Z.; Mariotto, A.; et al. SEER Cancer Statistics Review, 1975-2014. Available online: https://seer.cancer.gov/csr/ 1975_2014/ (accessed on 6 June 2020).

32. Rawla, P.; Sunkara, T.; Gaduputi, V. Epidemiology of Pancreatic Cancer: Global Trends, Etiology and Risk Factors. World J. Oncol. 2019, 10, 10-27. [CrossRef]

33. Ferlay, J.; Partensky, C.; Bray, F. More deaths from pancreatic cancer than breast cancer in the EU by 2017. Acta Oncol. 2016, 55, 1158-1160. [CrossRef] [PubMed]

34. De Angelis, R.; Sant, M.; Coleman, M.P.; Francisci, S.; Baili, P.; Pierannunzio, D.; Trama, A.; Visser, O.; Brenner, H.; Ardanaz, E.; et al. Cancer survival in Europe 1999-2007 by country and age: Results of EUROCARE-5-a population-based study. Lancet Oncol. 2014, 15, 23-34. [CrossRef]

35. ECIS-European Cancer Information System. Available online: https://ecis.jrc.ec.europa.eu/index.php (accessed on 6 June 2020).

36. Global Cancer Observatory. Available online: https://gco.iarc.fr (accessed on 6 June 2020).

37. Patra, K.C.; Bardeesy, N.; Mizukami, Y. Diversity of Precursor Lesions For Pancreatic Cancer: The Genetics and Biology of Intraductal Papillary Mucinous Neoplasm. Clin. Transl. Gastroenterol. 2017, 8, e86. [CrossRef] [PubMed]

38. Saiki, Y.; Horii, A. Molecular pathology of pancreatic cancer. Pathol. Int. 2014, 64, 10-19. [CrossRef] [PubMed]

39. Tada, M.; Ohashi, M.; Shiratori, Y.; Okudaira, T.; Komatsu, Y.; Kawabe, T.; Yoshida, H.; Machinami, R.; Kishi, K.; Omata, M. Analysis of K-ras gene mutation in hyperplastic duct cells of the pancreas without pancreatic disease. Gastroenterology 1996, 110, 227-231. [CrossRef] [PubMed]

40. Luttges, J.; Schlehe, B.; Menke, M.A.; Vogel, I.; Henne-Bruns, D.; Kloppel, G. The K-ras mutation pattern in pancreatic ductal adenocarcinoma usually is identical to that in associated normal, hyperplastic, and metaplastic ductal epithelium. Cancer 1999, 85, 1703-1710. [CrossRef]

41. Hezel, A.F.; Kimmelman, A.C.; Stanger, B.Z.; Bardeesy, N.; Depinho, R.A. Genetics and biology of pancreatic ductal adenocarcinoma. Genes Dev. 2006, 20, 1218-1249. [CrossRef]

42. Castellano-Megias, V.M.; Andres, C.I.; Lopez-Alonso, G.; Colina-Ruizdelgado, F. Pathological features and diagnosis of intraductal papillary mucinous neoplasm of the pancreas. World J. Gastrointest. Oncol. 2014, 6, 311-324. [CrossRef]

43. de Sousa Cavalcante, L.; Monteiro, G. Gemcitabine: Metabolism and molecular mechanisms of action, sensitivity and chemoresistance in pancreatic cancer. Eur. J. Pharmacol. 2014, 741, 8-16. [CrossRef]

44. Swayden, M.; Iovanna, J.; Soubeyran, P. Pancreatic cancer chemo-resistance is driven by tumor phenotype rather than tumor genotype. Heliyon 2018, 4, e01055. [CrossRef] 
45. Zeng, S.; Pottler, M.; Lan, B.; Grutzmann, R.; Pilarsky, C.; Yang, H. Chemoresistance in Pancreatic Cancer. Int. J. Mol. Sci. 2019, 20, 4504. [CrossRef] [PubMed]

46. Tan, Z.; Xu, J.; Zhang, B.; Shi, S.; Yu, X.; Liang, C. Hypoxia: A barricade to conquer the pancreatic cancer. Cell. Mol. Life Sci. CMLS 2020. [CrossRef] [PubMed]

47. Grasso, C.; Jansen, G.; Giovannetti, E. Drug resistance in pancreatic cancer: Impact of altered energy metabolism. Crit. Rev. Oncol. Hematol. 2017, 114, 139-152. [CrossRef] [PubMed]

48. Moeller, B.J.; Richardson, R.A.; Dewhirst, M.W. Hypoxia and radiotherapy: Opportunities for improved outcomes in cancer treatment. Cancer Metastasis Rev. 2007, 26, 241-248. [CrossRef]

49. Graham, K.; Unger, E. Overcoming tumor hypoxia as a barrier to radiotherapy, chemotherapy and immunotherapy in cancer treatment. Int. J. Nanomed. 2018, 13, 6049-6058. [CrossRef]

50. Rohwer, N.; Cramer, T. Hypoxia-mediated drug resistance: Novel insights on the functional interaction of HIFs and cell death pathways. Drug Resist. Updat. 2011, 14, 191-201. [CrossRef]

51. Daniel, S.K.; Sullivan, K.M.; Labadie, K.P.; Pillarisetty, V.G. Hypoxia as a barrier to immunotherapy in pancreatic adenocarcinoma. Clin. Transl. Med. 2019, 8, 10. [CrossRef]

52. Choi, S.Y.; Collins, C.C.; Gout, P.W.; Wang, Y. Cancer-generated lactic acid: A regulatory, immunosuppressive metabolite? J. Pathol. 2013, 230, 350-355. [CrossRef]

53. Daniel, C.; Bell, C.; Burton, C.; Harguindey, S.; Reshkin, S.J.; Rauch, C. The role of proton dynamics in the development and maintenance of multidrug resistance in cancer. Biochim. Biophys. Acta 2013, 1832, 606-617. [CrossRef]

54. Kitada, T.; Seki, S.; Sakaguchi, H.; Sawada, T.; Hirakawa, K.; Wakasa, K. Clinicopathological significance of hypoxia-inducible factor-1alpha expression in human pancreatic carcinoma. Histopathology 2003, 43, 550-555. [CrossRef]

55. Sun, H.C.; Qiu, Z.J.; Liu, J.; Sun, J.; Jiang, T.; Huang, K.J.; Yao, M.; Huang, C. Expression of hypoxia-inducible factor-1 alpha and associated proteins in pancreatic ductal adenocarcinoma and their impact on prognosis. Int. J. Oncol. 2007, 30, 1359-1367. [CrossRef] [PubMed]

56. Hiraoka, N.; Ino, Y.; Sekine, S.; Tsuda, H.; Shimada, K.; Kosuge, T.; Zavada, J.; Yoshida, M.; Yamada, K.; Koyama, T.; et al. Tumour necrosis is a postoperative prognostic marker for pancreatic cancer patients with a high interobserver reproducibility in histological evaluation. Br. J. Cancer 2010, 103, 1057-1065. [CrossRef]

57. Leppanen, J.; Helminen, O.; Huhta, H.; Kauppila, J.H.; Isohookana, J.; Haapasaari, K.M.; Parkkila, S.; Saarnio, J.; Lehenkari, P.P.; Karttunen, T.J. Weak HIF-1alpha expression indicates poor prognosis in resectable pancreatic ductal adenocarcinoma. World J. Surg. Oncol. 2018, 16, 127. [CrossRef] [PubMed]

58. Kaluz, S.; Kaluzova, M.; Opavsky, R.; Pastorekova, S.; Gibadulinova, A.; Dequiedt, F.; Kettmann, R.; Pastorek, J. Transcriptional regulation of the MN/CA 9 gene coding for the tumor-associated carbonic anhydrase IX. Identification and characterization of a proximal silencer element. J. Biol. Chem. 1999, 274, 32588-32595. [CrossRef] [PubMed]

59. Kaluzova, M.; Pastorekova, S.; Svastova, E.; Pastorek, J.; Stanbridge, E.J.; Kaluz, S. Characterization of the MN/CA 9 promoter proximal region: A role for specificity protein (SP) and activator protein 1 (AP1) factors. Biochem. J. 2001, 359, 669-677. [CrossRef] [PubMed]

60. Salnikow, K.; Aprelikova, O.; Ivanov, S.; Tackett, S.; Kaczmarek, M.; Karaczyn, A.; Yee, H.; Kasprzak, K.S.; Niederhuber, J. Regulation of hypoxia-inducible genes by ETS1 transcription factor. Carcinogenesis 2008, 29, 1493-1499. [CrossRef]

61. Kaluz, S.; Kaluzova, M.; Chrastina, A.; Olive, P.L.; Pastorekova, S.; Pastorek, J.; Lerman, M.I.; Stanbridge, E.J. Lowered oxygen tension induces expression of the hypoxia marker MN/carbonic anhydrase IX in the absence of hypoxia-inducible factor 1 alpha stabilization: A role for phosphatidylinositol 3'-kinase. Cancer Res. 2002, $62,4469-4477$.

62. Kopacek, J.; Barathova, M.; Dequiedt, F.; Sepelakova, J.; Kettmann, R.; Pastorek, J.; Pastorekova, S. MAPK pathway contributes to density- and hypoxia-induced expression of the tumor-associated carbonic anhydrase IX. Biochim. Biophys. Acta 2005, 1729, 41-49. [CrossRef]

63. Fishel, M.L.; Jiang, Y.; Rajeshkumar, N.V.; Scandura, G.; Sinn, A.L.; He, Y.; Shen, C.; Jones, D.R.; Pollok, K.E.; Ivan, M.; et al. Impact of APE1/Ref-1 redox inhibition on pancreatic tumor growth. Mol. Cancer Ther. 2011, 10, 1698-1708. [CrossRef] 
64. Logsdon, D.P.; Grimard, M.; Luo, M.; Shahda, S.; Jiang, Y.; Tong, Y.; Yu, Z.; Zyromski, N.; Schipani, E.; Carta, F.; et al. Regulation of HIF1alpha under Hypoxia by APE1/Ref-1 Impacts CA9 Expression: Dual Targeting in Patient-Derived 3D Pancreatic Cancer Models. Mol. Cancer Ther. 2016, 15, 2722-2732. [CrossRef]

65. Logsdon, D.P.; Shah, F.; Carta, F.; Supuran, C.T.; Kamocka, M.; Jacobsen, M.H.; Sandusky, G.E.; Kelley, M.R.; Fishel, M.L. Blocking HIF signaling via novel inhibitors of CA9 and APE1/Ref-1 dramatically affects pancreatic cancer cell survival. Sci. Rep. 2018, 8, 13759. [CrossRef] [PubMed]

66. Delitto, D.; Black, B.S.; Sorenson, H.L.; Knowlton, A.E.; Thomas, R.M.; Sarosi, G.A.; Moldawer, L.L.; Behrns, K.E.; Liu, C.; George, T.J.; et al. The inflammatory milieu within the pancreatic cancer microenvironment correlates with clinicopathologic parameters, chemoresistance and survival. BMC Cancer 2015, 15, 783. [CrossRef] [PubMed]

67. Hong, D.S.; Angelo, L.S.; Kurzrock, R. Interleukin-6 and its receptor in cancer: Implications for translational therapeutics. Cancer 2007, 110, 1911-1928. [CrossRef]

68. Sansone, P.; Storci, G.; Tavolari, S.; Guarnieri, T.; Giovannini, C.; Taffurelli, M.; Ceccarelli, C.; Santini, D.; Paterini, P.; Marcu, K.B.; et al. IL-6 triggers malignant features in mammospheres from human ductal breast carcinoma and normal mammary gland. J. Clin. Investig. 2007, 117, 3988-4002. [CrossRef]

69. Sansone, P.; Storci, G.; Giovannini, C.; Pandolfi, S.; Pianetti, S.; Taffurelli, M.; Santini, D.; Ceccarelli, C.; Chieco, P.; Bonafe, M. p66Shc/Notch-3 interplay controls self-renewal and hypoxia survival in human stem/progenitor cells of the mammary gland expanded in vitro as mammospheres. Stem Cells 2007, 25, 807-815. [CrossRef] [PubMed]

70. Shareef, M.M.; Udayakumar, T.S.; Sinha, V.K.; Saleem, S.M.; Griggs, W.W. Interaction of HIF-1alpha and Notch3 Is Required for the Expression of Carbonic Anhydrase 9 in Breast Carcinoma Cells. Genes Cancer 2013, 4, 513-523. [CrossRef]

71. Studebaker, A.W.; Storci, G.; Werbeck, J.L.; Sansone, P.; Sasser, A.K.; Tavolari, S.; Huang, T.; Chan, M.W.; Marini, F.C.; Rosol, T.J.; et al. Fibroblasts isolated from common sites of breast cancer metastasis enhance cancer cell growth rates and invasiveness in an interleukin-6-dependent manner. Cancer Res. 2008, 68, 9087-9095. [CrossRef]

72. Schoppmann, S.F.; Jesch, B.; Friedrich, J.; Jomrich, G.; Maroske, F.; Birner, P. Phosphorylation of signal transducer and activator of transcription 3 (STAT3) correlates with Her-2 status, carbonic anhydrase 9 expression and prognosis in esophageal cancer. Clin. Exp. Metastasis 2012, 29, 615-624. [CrossRef]

73. Korc, M.; Chandrasekar, B.; Yamanaka, Y.; Friess, H.; Buchier, M.; Beger, H.G. Overexpression of the epidermal growth factor receptor in human pancreatic cancer is associated with concomitant increases in the levels of epidermal growth factor and transforming growth factor alpha. J. Clin. Investig. 1992, 90, 1352-1360. [CrossRef]

74. Ardito, C.M.; Gruner, B.M.; Takeuchi, K.K.; Lubeseder-Martellato, C.; Teichmann, N.; Mazur, P.K.; Delgiorno, K.E.; Carpenter, E.S.; Halbrook, C.J.; Hall, J.C.; et al. EGF receptor is required for KRAS-induced pancreatic tumorigenesis. Cancer Cell 2012, 22, 304-317. [CrossRef]

75. McDonald, P.C.; Chafe, S.C.; Brown, W.S.; Saberi, S.; Swayampakula, M.; Venkateswaran, G.; Nemirovsky, O.; Gillespie, J.A.; Karasinska, J.M.; Kalloger, S.E.; et al. Regulation of pH by Carbonic Anhydrase 9 Mediates Survival of Pancreatic Cancer Cells With Activated KRAS in Response to Hypoxia. Gastroenterology 2019, 157, 823-837. [CrossRef] [PubMed]

76. Merchant, A.A.; Matsui, W. Targeting Hedgehog-A cancer stem cell pathway. Clin. Cancer Res. Off. J. Am. Assoc. Cancer Res. 2010, 16, 3130-3140. [CrossRef] [PubMed]

77. Gu, D.; Schlotman, K.E.; Xie, J. Deciphering the role of hedgehog signaling in pancreatic cancer. J. Biomed. Res. 2016, 30, 353-360. [CrossRef]

78. Bailey, J.M.; Swanson, B.J.; Hamada, T.; Eggers, J.P.; Singh, P.K.; Caffery, T.; Ouellette, M.M.; Hollingsworth, M.A. Sonic hedgehog promotes desmoplasia in pancreatic cancer. Clin. Cancer Res. Off. J. Am. Assoc. Cancer Res. 2008, 14, 5995-6004. [CrossRef] [PubMed]

79. Spivak-Kroizman, T.R.; Hostetter, G.; Posner, R.; Aziz, M.; Hu, C.; Demeure, M.J.; Von Hoff, D.; Hingorani, S.R.; Palculict, T.B.; Izzo, J.; et al. Hypoxia triggers hedgehog-mediated tumor-stromal interactions in pancreatic cancer. Cancer Res. 2013, 73, 3235-3247. [CrossRef]

80. Thayer, S.P.; di Magliano, M.P.; Heiser, P.W.; Nielsen, C.M.; Roberts, D.J.; Lauwers, G.Y.; Qi, Y.P.; Gysin, S.; Fernandez-del Castillo, C.; Yajnik, V.; et al. Hedgehog is an early and late mediator of pancreatic cancer tumorigenesis. Nature 2003, 425, 851-856. [CrossRef] 
81. Fritz, S.; Fernandez-del Castillo, C.; Iafrate, A.J.; Mino-Kenudson, M.; Neyhard, N.; LaFemina, J.; Stirman, A.; Warshaw, A.L.; Thayer, S.P. Novel xenograft and cell line derived from an invasive intraductal papillary mucinous neoplasm of the pancreas give new insights into molecular mechanisms. Pancreas 2010, 39, 308-314. [CrossRef]

82. Satoh, K.; Kanno, A.; Hamada, S.; Hirota, M.; Umino, J.; Masamune, A.; Egawa, S.; Motoi, F.; Unno, M.; Shimosegawa, T. Expression of Sonic hedgehog signaling pathway correlates with the tumorigenesis of intraductal papillary mucinous neoplasm of the pancreas. Oncol. Rep. 2008, 19, 1185-1190. [CrossRef]

83. Lei, J.; Ma, J.; Ma, Q.; Li, X.; Liu, H.; Xu, Q.; Duan, W.; Sun, Q.; Xu, J.; Wu, Z.; et al. Hedgehog signaling regulates hypoxia induced epithelial to mesenchymal transition and invasion in pancreatic cancer cells via a ligand-independent manner. Mol. Cancer 2013, 12, 66. [CrossRef]

84. Pietrobono, S.; Gagliardi, S.; Stecca, B. Non-canonical Hedgehog Signaling Pathway in Cancer: Activation of GLI Transcription Factors Beyond Smoothened. Front. Genet. 2019, 10, 556. [CrossRef]

85. Onishi, H.; Kai, M.; Odate, S.; Iwasaki, H.; Morifuji, Y.; Ogino, T.; Morisaki, T.; Nakashima, Y.; Katano, M. Hypoxia activates the hedgehog signaling pathway in a ligand-independent manner by upregulation of Smo transcription in pancreatic cancer. Cancer Sci. 2011, 102, 1144-1150. [CrossRef] [PubMed]

86. Nagai, S.; Nakamura, M.; Yanai, K.; Wada, J.; Akiyoshi, T.; Nakashima, H.; Ohuchida, K.; Sato, N.; Tanaka, M.; Katano, M. Gli1 contributes to the invasiveness of pancreatic cancer through matrix metalloproteinase-9 activation. Cancer Sci. 2008, 99, 1377-1384. [CrossRef] [PubMed]

87. Kinzler, K.W.; Vogelstein, B. The GLI gene encodes a nuclear protein which binds specific sequences in the human genome. Mol. Cell. Biol. 1990, 10, 634-642. [CrossRef]

88. Winklmayr, M.; Schmid, C.; Laner-Plamberger, S.; Kaser, A.; Aberger, F.; Eichberger, T.; Frischauf, A.M. Non-consensus GLI binding sites in Hedgehog target gene regulation. BMC Mol. Biol. 2010, 11, 2. [CrossRef] [PubMed]

89. Fornes, O.; Castro-Mondragon, J.A.; Khan, A.; van der Lee, R.; Zhang, X.; Richmond, P.A.; Modi, B.P.; Correard, S.; Gheorghe, M.; Baranasic, D.; et al. JASPAR 2020: Update of the open-access database of transcription factor binding profiles. Nucleic Acids Res. 2020, 48, D87-D92. [CrossRef] [PubMed]

90. Cartharius, K.; Frech, K.; Grote, K.; Klocke, B.; Haltmeier, M.; Klingenhoff, A.; Frisch, M.; Bayerlein, M.; Werner, T. MatInspector and beyond: Promoter analysis based on transcription factor binding sites. Bioinformatics 2005, 21, 2933-2942. [CrossRef]

91. Quandt, K.; Frech, K.; Karas, H.; Wingender, E.; Werner, T. MatInd and MatInspector: New fast and versatile tools for detection of consensus matches in nucleotide sequence data. Nucleic Acids Res. 1995, 23, 4878-4884. [CrossRef]

92. Duell, E.J.; Lucenteforte, E.; Olson, S.H.; Bracci, P.M.; Li, D.; Risch, H.A.; Silverman, D.T.; Ji, B.T.; Gallinger, S.; Holly, E.A.; et al. Pancreatitis and pancreatic cancer risk: A pooled analysis in the International Pancreatic Cancer Case-Control Consortium (PanC4). Ann. Oncol. 2012, 23, 2964-2970. [CrossRef]

93. Shah, A.U.; Sarwar, A.; Orabi, A.I.; Gautam, S.; Grant, W.M.; Park, A.J.; Shah, A.U.; Liu, J.; Mistry, P.K.; Jain, D.; et al. Protease activation during in vivo pancreatitis is dependent on calcineurin activation. Am. J. Physiol. Gastrointest. Liver Physiol. 2009, 297, G967-G973. [CrossRef]

94. Yadav, D.; Lowenfels, A.B. The epidemiology of pancreatitis and pancreatic cancer. Gastroenterology 2013, 144, 1252-1261. [CrossRef]

95. Dhar, P.; Kalghatgi, S.; Saraf, V. Pancreatic cancer in chronic pancreatitis. Indian J. Surg. Oncol. 2015, 6, 57-62. [CrossRef] [PubMed]

96. Jensen, J.N.; Cameron, E.; Garay, M.V.; Starkey, T.W.; Gianani, R.; Jensen, J. Recapitulation of elements of embryonic development in adult mouse pancreatic regeneration. Gastroenterology 2005, 128, 728-741. [CrossRef] [PubMed]

97. Pinho, A.V.; Rooman, I.; Reichert, M.; De Medts, N.; Bouwens, L.; Rustgi, A.K.; Real, F.X. Adult pancreatic acinar cells dedifferentiate to an embryonic progenitor phenotype with concomitant activation of a senescence programme that is present in chronic pancreatitis. Gut 2011, 60, 958-966. [CrossRef] [PubMed]

98. Pan, F.C.; Bankaitis, E.D.; Boyer, D.; Xu, X.; Van de Casteele, M.; Magnuson, M.A.; Heimberg, H.; Wright, C.V. Spatiotemporal patterns of multipotentiality in Ptf1a-expressing cells during pancreas organogenesis and injury-induced facultative restoration. Development 2013, 140, 751-764. [CrossRef] [PubMed] 
99. Liou, G.Y.; Doppler, H.; Necela, B.; Krishna, M.; Crawford, H.C.; Raimondo, M.; Storz, P. Macrophage-secreted cytokines drive pancreatic acinar-to-ductal metaplasia through NF-kappaB and MMPs. J. Cell Biol. 2013, 202, 563-577. [CrossRef]

100. Kopp, J.L.; von Figura, G.; Mayes, E.; Liu, F.F.; Dubois, C.L.; Morris, J.P.t.; Pan, F.C.; Akiyama, H.; Wright, C.V.; Jensen, K.; et al. Identification of Sox9-dependent acinar-to-ductal reprogramming as the principal mechanism for initiation of pancreatic ductal adenocarcinoma. Cancer Cell 2012, 22, 737-750. [CrossRef]

101. Piccinini, A.M.; Midwood, K.S. DAMPening inflammation by modulating TLR signalling. Mediat. Inflamm. 2010, 2010. [CrossRef]

102. Veyrat, M.; Durand, S.; Classe, M.; Glavan, T.M.; Oker, N.; Kapetanakis, N.I.; Jiang, X.; Gelin, A.; Herman, P.; Casiraghi, O.; et al. Stimulation of the toll-like receptor 3 promotes metabolic reprogramming in head and neck carcinoma cells. Oncotarget 2016, 7, 82580-82593. [CrossRef]

103. Ochi, A.; Graffeo, C.S.; Zambirinis, C.P.; Rehman, A.; Hackman, M.; Fallon, N.; Barilla, R.M.; Henning, J.R.; Jamal, M.; Rao, R.; et al. Toll-like receptor 7 regulates pancreatic carcinogenesis in mice and humans. J. Clin. Investig. 2012, 122, 4118-4129. [CrossRef]

104. Leppanen, J.; Helminen, O.; Huhta, H.; Kauppila, J.H.; Isohookana, J.; Haapasaari, K.M.; Karihtala, P.; Parkkila, S.; Saarnio, J.; Lehenkari, P.P.; et al. Toll-like receptors 2, 4 and 9 and hypoxia markers HIF-1alpha and CAIX in pancreatic intraepithelial neoplasia. APMIS Acta Pathol. Microbiol. Immunol. Scand. 2018, 126, 852-863. [CrossRef]

105. Grimmig, T.; Matthes, N.; Hoeland, K.; Tripathi, S.; Chandraker, A.; Grimm, M.; Moench, R.; Moll, E.M.; Friess, H.; Tsaur, I.; et al. TLR7 and TLR8 expression increases tumor cell proliferation and promotes chemoresistance in human pancreatic cancer. Int. J. Oncol. 2015, 47, 857-866. [CrossRef] [PubMed]

106. Helminen, O.; Huhta, H.; Leppanen, J.; Kauppila, J.H.; Takala, H.; Lehenkari, P.P.; Saarnio, J.; Karttunen, T.J. Nuclear localization of Toll-like receptor 5 in Barrett's esophagus and esophageal adenocarcinoma is associated with metastatic behavior. Virchows Arch. Int. J. Pathol. 2016, 469, 465-470. [CrossRef] [PubMed]

107. Grimm, M.; Kim, M.; Rosenwald, A.; Heemann, U.; Germer, C.T.; Waaga-Gasser, A.M.; Gasser, M. Toll-like receptor (TLR) 7 and TLR8 expression on CD133+ cells in colorectal cancer points to a specific role for inflammation-induced TLRs in tumourigenesis and tumour progression. Eur. J. Cancer 2010, 46, 2849-2857. [CrossRef] [PubMed]

108. Akira, S.; Takeda, K. Toll-like receptor signalling. Nat. Rev. Immunol. 2004, 4, 499-511. [CrossRef]

109. Harris, R.E. Cyclooxygenase-2 (cox-2) and the inflammogenesis of cancer. Subcell. Biochem. 2007, 42, 93-126. [CrossRef]

110. Chang, Y.J.; Wu, M.S.; Lin, J.T.; Chen, C.C. Helicobacter pylori-Induced invasion and angiogenesis of gastric cells is mediated by cyclooxygenase-2 induction through TLR2/TLR9 and promoter regulation. J. Immunol. 2005, 175, 8242-8252. [CrossRef]

111. Sansone, P.; Piazzi, G.; Paterini, P.; Strillacci, A.; Ceccarelli, C.; Minni, F.; Biasco, G.; Chieco, P.; Bonafe, M. Cyclooxygenase-2/carbonic anhydrase-IX up-regulation promotes invasive potential and hypoxia survival in colorectal cancer cells. J. Cell. Mol. Med. 2009, 13, 3876-3887. [CrossRef]

112. Mews, P.; Phillips, P.; Fahmy, R.; Korsten, M.; Pirola, R.; Wilson, J.; Apte, M. Pancreatic stellate cells respond to inflammatory cytokines: Potential role in chronic pancreatitis. Gut 2002, 50, 535-541. [CrossRef]

113. Schneider, E.; Schmid-Kotsas, A.; Zhao, J.; Weidenbach, H.; Schmid, R.M.; Menke, A.; Adler, G.; Waltenberger, J.; Grunert, A.; Bachem, M.G. Identification of mediators stimulating proliferation and matrix synthesis of rat pancreatic stellate cells. Am. J. Physiol. Cell Physiol. 2001, 281, C532-C543. [CrossRef]

114. Apte, M.V.; Haber, P.S.; Darby, S.J.; Rodgers, S.C.; McCaughan, G.W.; Korsten, M.A.; Pirola, R.C.; Wilson, J.S. Pancreatic stellate cells are activated by proinflammatory cytokines: Implications for pancreatic fibrogenesis. Gut 1999, 44, 534-541. [CrossRef]

115. Apte, M.; Pirola, R.; Wilson, J. The fibrosis of chronic pancreatitis: New insights into the role of pancreatic stellate cells. Antioxid. Redox Signal. 2011, 15, 2711-2722. [CrossRef] [PubMed]

116. Kuhlicke, J.; Frick, J.S.; Morote-Garcia, J.C.; Rosenberger, P.; Eltzschig, H.K. Hypoxia inducible factor (HIF)-1 coordinates induction of Toll-like receptors TLR2 and TLR6 during hypoxia. PLoS ONE 2007, 2, e1364. [CrossRef] [PubMed]

117. Fan, P.; Zhang, J.J.; Wang, B.; Wu, H.Q.; Zhou, S.X.; Wang, C.Y.; Zhang, J.H.; Tian, Y.; Wu, H.S. Hypoxiainducible factor-1 up-regulates the expression of Toll-like receptor 4 in pancreatic cancer cells under hypoxic conditions. Pancreatology 2012, 12, 170-178. [CrossRef] [PubMed] 
118. Sandholm, J.; Tuomela, J.; Kauppila, J.H.; Harris, K.W.; Graves, D.; Selander, K.S. Hypoxia regulates Toll-like receptor-9 expression and invasive function in human brain cancer cells in vitro. Oncol. Lett. 2014, 8, 266-274. [CrossRef]

119. Zhang, J.J.; Wu, H.S.; Wang, L.; Tian, Y.; Zhang, J.H.; Wu, H.L. Expression and significance of TLR4 and HIF-1alpha in pancreatic ductal adenocarcinoma. World J. Gastroenterol. 2010, 16, 2881-2888. [CrossRef]

120. Panisova, E.; Kery, M.; Sedlakova, O.; Brisson, L.; Debreova, M.; Sboarina, M.; Sonveaux, P.; Pastorekova, S.; Svastova, E. Lactate stimulates CA IX expression in normoxic cancer cells. Oncotarget 2017, 8, 77819-77835. [CrossRef]

121. Juhasz, M.; Chen, J.; Lendeckel, U.; Kellner, U.; Kasper, H.U.; Tulassay, Z.; Pastorekova, S.; Malfertheiner, P.; Ebert, M.P. Expression of carbonic anhydrase IX in human pancreatic cancer. Aliment. Pharmacol. Ther. 2003, 18, 837-846. [CrossRef]

122. Wang, W.Q.; Liu, L.; Xu, H.X.; Luo, G.P.; Chen, T.; Wu, C.T.; Xu, Y.F.; Xu, J.; Liu, C.; Zhang, B.; et al. Intratumoral alpha-SMA enhances the prognostic potency of CD34 associated with maintenance of microvessel integrity in hepatocellular carcinoma and pancreatic cancer. PLoS ONE 2013, 8, e71189. [CrossRef]

123. Chen, D.T.; Davis-Yadley, A.H.; Huang, P.Y.; Husain, K.; Centeno, B.A.; Permuth-Wey, J.; Pimiento, J.M.; Malafa, M. Prognostic Fifteen-Gene Signature for Early Stage Pancreatic Ductal Adenocarcinoma. PLoS ONE 2015, 10, e0133562. [CrossRef]

124. Ino, Y.; Yamazaki-Itoh, R.; Oguro, S.; Shimada, K.; Kosuge, T.; Zavada, J.; Kanai, Y.; Hiraoka, N. Arginase II expressed in cancer-associated fibroblasts indicates tissue hypoxia and predicts poor outcome in patients with pancreatic cancer. PLoS ONE 2013, 8, e55146. [CrossRef]

125. Bronte, V.; Kasic, T.; Gri, G.; Gallana, K.; Borsellino, G.; Marigo, I.; Battistini, L.; Iafrate, M.; Prayer-Galetti, T.; Pagano, F.; et al. Boosting antitumor responses of $\mathrm{T}$ lymphocytes infiltrating human prostate cancers. J. Exp. Med. 2005, 201, 1257-1268. [CrossRef] [PubMed]

126. Ciernikova, S.; Earl, J.; Garcia Bermejo, M.L.; Stevurkova, V.; Carrato, A.; Smolkova, B. Epigenetic Landscape in Pancreatic Ductal Adenocarcinoma: On the Way to Overcoming Drug Resistance? Int. J. Mol. Sci. 2020, 21, 4091. [CrossRef] [PubMed]

127. Rachagani, S.; Macha, M.A.; Ponnusamy, M.P.; Haridas, D.; Kaur, S.; Jain, M.; Batra, S.K. MUC4 potentiates invasion and metastasis of pancreatic cancer cells through stabilization of fibroblast growth factor receptor 1. Carcinogenesis 2012, 33, 1953-1964. [CrossRef] [PubMed]

128. Torres, M.P.; Chakraborty, S.; Souchek, J.; Batra, S.K. Mucin-based targeted pancreatic cancer therapy. Curr. Pharm. Des. 2012, 18, 2472-2481. [CrossRef]

129. Yokoyama, S.; Higashi, M.; Kitamoto, S.; Oeldorf, M.; Knippschild, U.; Kornmann, M.; Maemura, K.; Kurahara, H.; Wiest, E.; Hamada, T.; et al. Aberrant methylation of MUC1 and MUC4 promoters are potential prognostic biomarkers for pancreatic ductal adenocarcinomas. Oncotarget 2016, 7, 42553-42565. [CrossRef]

130. Yamada, N.; Kitamoto, S.; Yokoyama, S.; Hamada, T.; Goto, M.; Tsutsumida, H.; Higashi, M.; Yonezawa, S. Epigenetic regulation of mucin genes in human cancers. Clin. Epigenetics 2011, 2, 85-96. [CrossRef]

131. Shahrzad, S.; Bertrand, K.; Minhas, K.; Coomber, B.L. Induction of DNA hypomethylation by tumor hypoxia. Epigenetics 2007, 2, 119-125. [CrossRef]

132. Choudhry, H.; Harris, A.L. Advances in Hypoxia-Inducible Factor Biology. Cell Metab. 2018, 27, $281-298$. [CrossRef]

133. Thienpont, B.; Steinbacher, J.; Zhao, H.; D’Anna, F.; Kuchnio, A.; Ploumakis, A.; Ghesquiere, B.; Van Dyck, L.; Boeckx, B.; Schoonjans, L.; et al. Tumour hypoxia causes DNA hypermethylation by reducing TET activity. Nature 2016, 537, 63-68. [CrossRef]

134. Pasca di Magliano, M.; Biankin, A.V.; Heiser, P.W.; Cano, D.A.; Gutierrez, P.J.; Deramaudt, T.; Segara, D.; Dawson, A.C.; Kench, J.G.; Henshall, S.M.; et al. Common activation of canonical Wnt signaling in pancreatic adenocarcinoma. PLoS ONE 2007, 2, e1155. [CrossRef]

135. Zeng, G.; Germinaro, M.; Micsenyi, A.; Monga, N.K.; Bell, A.; Sood, A.; Malhotra, V.; Sood, N.; Midda, V.; Monga, D.K.; et al. Aberrant Wnt/beta-catenin signaling in pancreatic adenocarcinoma. Neoplasia 2006, 8, 279-289. [CrossRef] [PubMed]

136. Wang, L.; Heidt, D.G.; Lee, C.J.; Yang, H.; Logsdon, C.D.; Zhang, L.; Fearon, E.R.; Ljungman, M.; Simeone, D.M. Oncogenic function of ATDC in pancreatic cancer through Wnt pathway activation and beta-catenin stabilization. Cancer Cell 2009, 15, 207-219. [CrossRef] 
137. Hu, W.; Wang, Z.; Zhang, S.; Lu, X.; Wu, J.; Yu, K.; Ji, A.; Lu, W.; Wang, Z.; Wu, J.; et al. IQGAP1 promotes pancreatic cancer progression and epithelial-mesenchymal transition (EMT) through Wnt/beta-catenin signaling. Sci. Rep. 2019, 9, 7539. [CrossRef] [PubMed]

138. Omori, Y.; Ono, Y.; Tanino, M.; Karasaki, H.; Yamaguchi, H.; Furukawa, T.; Enomoto, K.; Ueda, J.; Sumi, A.; Katayama, J.; et al. Pathways of Progression From Intraductal Papillary Mucinous Neoplasm to Pancreatic Ductal Adenocarcinoma Based on Molecular Features. Gastroenterology 2019, 156, 647-661 e642. [CrossRef] [PubMed]

139. Sato, N.; Fukushima, N.; Maitra, A.; Iacobuzio-Donahue, C.A.; van Heek, N.T.; Cameron, J.L.; Yeo, C.J.; Hruban, R.H.; Goggins, M. Gene expression profiling identifies genes associated with invasive intraductal papillary mucinous neoplasms of the pancreas. Am. J. Pathol. 2004, 164, 903-914. [CrossRef]

140. Hruz, T.; Laule, O.; Szabo, G.; Wessendorp, F.; Bleuler, S.; Oertle, L.; Widmayer, P.; Gruissem, W.; Zimmermann, P. Genevestigator v3: A reference expression database for the meta-analysis of transcriptomes. Adv. Bioinform. 2008, 2008, 420747. [CrossRef] [PubMed]

141. Mohammad, G.H.; Olde Damink, S.W.; Malago, M.; Dhar, D.K.; Pereira, S.P. Pyruvate Kinase M2 and Lactate Dehydrogenase A Are Overexpressed in Pancreatic Cancer and Correlate with Poor Outcome. PLoS ONE 2016, 11, e0151635. [CrossRef] [PubMed]

142. Penheiter, A.R.; Deelchand, D.K.; Kittelson, E.; Damgard, S.E.; Murphy, S.J.; O’Brien, D.R.; Bamlet, W.R.; Passow, M.R.; Smyrk, T.C.; Couch, F.J.; et al. Identification of a pyruvate-to-lactate signature in pancreatic intraductal papillary mucinous neoplasms. Pancreatology 2018, 18, 46-53. [CrossRef]

143. Pastorekova, S.; Zavadova, Z.; Kostal, M.; Babusikova, O.; Zavada, J. A novel quasi-viral agent, MaTu, is a two-component system. Virology 1992, 187, 620-626. [CrossRef]

144. Takacova, M.; Bartosova, M.; Skvarkova, L.; Zatovicova, M.; Vidlickova, I.; Csaderova, L.; Barathova, M.; Breza, J., Jr.; Bujdak, P.; Pastorek, J.; et al. Carbonic anhydrase IX is a clinically significant tissue and serum biomarker associated with renal cell carcinoma. Oncol. Lett. 2013, 5, 191-197. [CrossRef]

145. D'Angelo, A.; Sobhani, N.; Roviello, G.; Bagby, S.; Bonazza, D.; Bottin, C.; Giudici, F.; Zanconati, F.; De Manzini, N.; Guglielmi, A.; et al. Tumour infiltrating lymphocytes and immune-related genes as predictors of outcome in pancreatic adenocarcinoma. PLoS ONE 2019, 14, e0219566. [CrossRef] [PubMed]

146. Gibadulinova, A.; Bullova, P.; Strnad, H.; Pohlodek, K.; Jurkovicova, D.; Takacova, M.; Pastorekova, S.; Svastova, E. CAIX-Mediated Control of LIN28/let-7 Axis Contributes to Metabolic Adaptation of Breast Cancer Cells to Hypoxia. Int. J. Mol. Sci. 2020, 21, 4299. [CrossRef] [PubMed]

147. Cruz-Monserrate, Z.; Roland, C.L.; Deng, D.; Arumugam, T.; Moshnikova, A.; Andreev, O.A.; Reshetnyak, Y.K.; Logsdon, C.D. Targeting pancreatic ductal adenocarcinoma acidic microenvironment. Sci. Rep. 2014, 4, 4410. [CrossRef] [PubMed]

148. Goldenberg, J.M.; Cardenas-Rodriguez, J.; Pagel, M.D. Preliminary Results that Assess Metformin Treatment in a Preclinical Model of Pancreatic Cancer Using Simultaneous [(18)F]FDG PET and acidoCEST MRI. Mol. Imaging Biol. 2018, 20, 575-583. [CrossRef]

149. Chen, L.Q.; Howison, C.M.; Spier, C.; Stopeck, A.T.; Malm, S.W.; Pagel, M.D.; Baker, A.F. Assessment of carbonic anhydrase IX expression and extracellular $\mathrm{pH}$ in B-cell lymphoma cell line models. Leuk Lymphoma 2015, 56, 1432-1439. [CrossRef]

150. Pedersen, S.F.; Novak, I.; Alves, F.; Schwab, A.; Pardo, L.A. Alternating pH landscapes shape epithelial cancer initiation and progression: Focus on pancreatic cancer. Bioessays 2017, 39. [CrossRef]

151. Oosterwijk-Wakka, J.C.; Boerman, O.C.; Mulders, P.F.; Oosterwijk, E. Application of monoclonal antibody G250 recognizing carbonic anhydrase IX in renal cell carcinoma. Int. J. Mol. Sci. 2013, 14, 11402-11423. [CrossRef]

152. Lee, K.E.; Spata, M.; Bayne, L.J.; Buza, E.L.; Durham, A.C.; Allman, D.; Vonderheide, R.H.; Simon, M.C. Hif1a Deletion Reveals Pro-Neoplastic Function of B Cells in Pancreatic Neoplasia. Cancer Discov. 2016, 6, 256-269. [CrossRef]

153. Shukla, S.K.; Purohit, V.; Mehla, K.; Gunda, V.; Chaika, N.V.; Vernucci, E.; King, R.J.; Abrego, J.; Goode, G.D.; Dasgupta, A.; et al. MUC1 and HIF-1alpha Signaling Crosstalk Induces Anabolic Glucose Metabolism to Impart Gemcitabine Resistance to Pancreatic Cancer. Cancer Cell 2017, 32, 392. [CrossRef]

154. Lardner, A. The effects of extracellular $\mathrm{pH}$ on immune function. J. Leukoc Biol. 2001, 69, 522-530. 
155. Damgaci, S.; Ibrahim-Hashim, A.; Enriquez-Navas, P.M.; Pilon-Thomas, S.; Guvenis, A.; Gillies, R.J. Hypoxia and acidosis: Immune suppressors and therapeutic targets. Immunology 2018, 154, 354-362. [CrossRef] [PubMed]

156. Ward, C.; Meehan, J.; Gray, M.E.; Murray, A.F.; Argyle, D.J.; Kunkler, I.H.; Langdon, S.P. The impact of tumour $\mathrm{pH}$ on cancer progression: Strategies for.clinical intervention. Explor. Target. Anti Tumor Ther. 2020, 1, 71-100. [CrossRef]

157. Pilon-Thomas, S.; Kodumudi, K.N.; El-Kenawi, A.E.; Russell, S.; Weber, A.M.; Luddy, K.; Damaghi, M.; Wojtkowiak, J.W.; Mule, J.J.; Ibrahim-Hashim, A.; et al. Neutralization of Tumor Acidity Improves Antitumor Responses to Immunotherapy. Cancer Res. 2016, 76, 1381-1390. [CrossRef] [PubMed]

158. Ibrahim Hashim, A.A.; Abrahams, D.; Xu, L.; Centeno, B.; Sunassee, E.; Abddelgader, R.; Dubois, L.; Lambin, P.; Gatenby, R.A.; Gillies, R.J. Targeting tumor acidity with the LDHA inhibitor (FX11) and CAIX inhibitor (DH348) overcomes resistance to PD-1 blockade and inhibits metastasis in a pancreatic cancer model. In Proceedings of the AACR Annual Meeting 2017, Washington, DC, USA, 1-5 April 2017; Volume 77. Abstract nr 5932. [CrossRef]

159. Robey, I.F.; Baggett, B.K.; Kirkpatrick, N.D.; Roe, D.J.; Dosescu, J.; Sloane, B.F.; Hashim, A.I.; Morse, D.L.; Raghunand, N.; Gatenby, R.A.; et al. Bicarbonate increases tumor $\mathrm{pH}$ and inhibits spontaneous metastases. Cancer Res. 2009, 69, 2260-2268. [CrossRef]

160. Chafe, S.C.; McDonald, P.C.; Saberi, S.; Nemirovsky, O.; Venkateswaran, G.; Burugu, S.; Gao, D.; Delaidelli, A.; Kyle, A.H.; Baker, J.H.E.; et al. Targeting Hypoxia-Induced Carbonic Anhydrase IX Enhances Immune-Checkpoint Blockade Locally and Systemically. Cancer Immunol. Res. 2019, 7, 1064-1078. [CrossRef]

161. Wong, J.C.; Raman, S. Surgical resectability of pancreatic adenocarcinoma: CTA. Abdom Imaging 2010, 35, 471-480. [CrossRef]

162. Conroy, T.; Desseigne, F.; Ychou, M.; Bouche, O.; Guimbaud, R.; Becouarn, Y.; Adenis, A.; Raoul, J.L.; Gourgou-Bourgade, S.; de la Fouchardiere, C.; et al. FOLFIRINOX versus gemcitabine for metastatic pancreatic cancer. N. Engl. J. Med. 2011, 364, 1817-1825. [CrossRef]

163. Buchler, P.; Reber, H.A.; Buchler, M.; Shrinkante, S.; Buchler, M.W.; Friess, H.; Semenza, G.L.; Hines, O.J. Hypoxia-inducible factor 1 regulates vascular endothelial growth factor expression in human pancreatic cancer. Pancreas 2003, 26, 56-64. [CrossRef]

164. McIntyre, A.; Patiar, S.; Wigfield, S.; Li, J.L.; Ledaki, I.; Turley, H.; Leek, R.; Snell, C.; Gatter, K.; Sly, W.S.; et al. Carbonic anhydrase IX promotes tumor growth and necrosis in vivo and inhibition enhances anti-VEGF therapy. Clin. Cancer Res. Off. J. Am. Assoc. Cancer Res. 2012, 18, 3100-3111. [CrossRef]

165. Brown-Glaberman, U.; Marron, M.; Chalasani, P.; Livingston, R.; Iannone, M.; Specht, J.; Stopeck, A.T. Circulating Carbonic Anhydrase IX and Antiangiogenic Therapy in Breast Cancer. Dis. Markers 2016, 2016, 9810383. [CrossRef]

166. Kindler, H.L.; Friberg, G.; Singh, D.A.; Locker, G.; Nattam, S.; Kozloff, M.; Taber, D.A.; Karrison, T.; Dachman, A.; Stadler, W.M.; et al. Phase II trial of bevacizumab plus gemcitabine in patients with advanced pancreatic cancer. J. Clin. Oncol. Off. J. Am. Soc. Clin. Oncol. 2005, 23, 8033-8040. [CrossRef] [PubMed]

167. Rezai, P.; Yaghmai, V.; Tochetto, S.M.; Galizia, M.S.; Miller, F.H.; Mulcahy, M.F.; Small, W., Jr. Change in the growth rate of localized pancreatic adenocarcinoma in response to gemcitabine, bevacizumab, and radiation therapy on MDCT. Int. J. Radiat. Oncol. Biol. Phys. 2011, 81, 452-459. [CrossRef] [PubMed]

168. Crane, C.H.; Winter, K.; Regine, W.F.; Safran, H.; Rich, T.A.; Curran, W.; Wolff, R.A.; Willett, C.G. Phase II study of bevacizumab with concurrent capecitabine and radiation followed by maintenance gemcitabine and bevacizumab for locally advanced pancreatic cancer: Radiation Therapy Oncology Group RTOG 0411. J. Clin. Oncol. Off. J. Am. Soc. Clin. Oncol. 2009, 27, 4096-4102. [CrossRef] [PubMed]

169. Breuer, S.; Maimon, O.; Appelbaum, L.; Peretz, T.; Hubert, A. TL-118-anti-angiogenic treatment in pancreatic cancer: A case report. Med. Oncol. 2013, 30, 585. [CrossRef]

170. O’Reilly, E.M.; Niedzwiecki, D.; Hall, M.; Hollis, D.; Bekaii-Saab, T.; Pluard, T.; Douglas, K.; Abou-Alfa, G.K.; Kindler, H.L.; Schilsky, R.L.; et al. A Cancer and Leukemia Group B phase II study of sunitinib malate in patients with previously treated metastatic pancreatic adenocarcinoma (CALGB 80603). Oncologist 2010, 15, 1310-1319. [CrossRef] 
171. Kindler, H.L.; Ioka, T.; Richel, D.J.; Bennouna, J.; Letourneau, R.; Okusaka, T.; Funakoshi, A.; Furuse, J.; Park, Y.S.; Ohkawa, S.; et al. Axitinib plus gemcitabine versus placebo plus gemcitabine in patients with advanced pancreatic adenocarcinoma: A double-blind randomised phase 3 study. Lancet Oncol. 2011, 12, 256-262. [CrossRef]

172. Deplanque, G.; Demarchi, M.; Hebbar, M.; Flynn, P.; Melichar, B.; Atkins, J.; Nowara, E.; Moye, L.; Piquemal, D.; Ritter, D.; et al. A randomized, placebo-controlled phase III trial of masitinib plus gemcitabine in the treatment of advanced pancreatic cancer. Ann. Oncol. 2015, 26, 1194-1200. [CrossRef]

173. Cascinu, S.; Berardi, R.; Labianca, R.; Siena, S.; Falcone, A.; Aitini, E.; Barni, S.; Di Costanzo, F.; Dapretto, E.; Tonini, G.; et al. Cetuximab plus gemcitabine and cisplatin compared with gemcitabine and cisplatin alone in patients with advanced pancreatic cancer: A randomised, multicentre, phase II trial. Lancet Oncol. 2008, 9, 39-44. [CrossRef]

174. Philip, P.A.; Benedetti, J.; Corless, C.L.; Wong, R.; O’Reilly, E.M.; Flynn, P.J.; Rowland, K.M.; Atkins, J.N.; Mirtsching, B.C.; Rivkin, S.E.; et al. Phase III study comparing gemcitabine plus cetuximab versus gemcitabine in patients with advanced pancreatic adenocarcinoma: Southwest Oncology Group-directed intergroup trial S0205. J. Clin. Oncol. Off. J. Am. Soc. Clin. Oncol. 2010, 28, 3605-3610. [CrossRef]

175. Schultheis, B.; Reuter, D.; Ebert, M.P.; Siveke, J.; Kerkhoff, A.; Berdel, W.E.; Hofheinz, R.; Behringer, D.M.; Schmidt, W.E.; Goker, E.; et al. Gemcitabine combined with the monoclonal antibody nimotuzumab is an active first-line regimen in KRAS wildtype patients with locally advanced or metastatic pancreatic cancer: A multicenter, randomized phase IIb study. Ann. Oncol. 2017, 28, 2429-2435. [CrossRef]

176. Wang, J.P.; Wu, C.Y.; Yeh, Y.C.; Shyr, Y.M.; Wu, Y.Y.; Kuo, C.Y.; Hung, Y.P.; Chen, M.H.; Lee, W.P.; Luo, J.C.; et al. Erlotinib is effective in pancreatic cancer with epidermal growth factor receptor mutations: A randomized, open-label, prospective trial. Oncotarget 2015, 6, 18162-18173. [CrossRef] [PubMed]

177. Moore, M.J.; Goldstein, D.; Hamm, J.; Figer, A.; Hecht, J.R.; Gallinger, S.; Au, H.J.; Murawa, P.; Walde, D.; Wolff, R.A.; et al. Erlotinib plus gemcitabine compared with gemcitabine alone in patients with advanced pancreatic cancer: A phase III trial of the National Cancer Institute of Canada Clinical Trials Group. J. Clin. Oncol. Off. J. Am. Soc. Clin. Oncol. 2007, 25, 1960-1966. [CrossRef] [PubMed]

178. Ko, A.H.; Venook, A.P.; Bergsland, E.K.; Kelley, R.K.; Korn, W.M.; Dito, E.; Schillinger, B.; Scott, J.; Hwang, J.; Tempero, M.A. A phase II study of bevacizumab plus erlotinib for gemcitabine-refractory metastatic pancreatic cancer. Cancer Chemother. Pharmacol. 2010, 66, 1051-1057. [CrossRef] [PubMed]

179. Hu, C.; Dadon, T.; Chenna, V.; Yabuuchi, S.; Bannerji, R.; Booher, R.; Strack, P.; Azad, N.; Nelkin, B.D.; Maitra, A. Combined Inhibition of Cyclin-Dependent Kinases (Dinaciclib) and AKT (MK-2206) Blocks Pancreatic Tumor Growth and Metastases in Patient-Derived Xenograft Models. Mol. Cancer Ther. 2015, 14, 1532-1539. [CrossRef]

180. Yoon, H.; Kim, D.J.; Ahn, E.H.; Gellert, G.C.; Shay, J.W.; Ahn, C.H.; Lee, Y.B. Antitumor activity of a novel antisense oligonucleotide against Akt1. J. Cell. Biochem. 2009, 108, 832-838. [CrossRef]

181. Meng, F.; Evans, J.W.; Bhupathi, D.; Banica, M.; Lan, L.; Lorente, G.; Duan, J.X.; Cai, X.; Mowday, A.M.; Guise, C.P.; et al. Molecular and cellular pharmacology of the hypoxia-activated prodrug TH-302. Mol. Cancer Ther. 2012, 11, 740-751. [CrossRef]

182. Sun, J.D.; Liu, Q.; Ahluwalia, D.; Li, W.; Meng, F.; Wang, Y.; Bhupathi, D.; Ruprell, A.S.; Hart, C.P. Efficacy and safety of the hypoxia-activated prodrug TH-302 in combination with gemcitabine and nabpaclitaxel in human tumor xenograft models of pancreatic cancer. Cancer Biol. Ther. 2015, 16, 438-449. [CrossRef]

183. Borad, M.J.; Reddy, S.G.; Bahary, N.; Uronis, H.E.; Sigal, D.; Cohn, A.L.; Schelman, W.R.; Stephenson, J., Jr.; Chiorean, E.G.; Rosen, P.J.; et al. Randomized Phase II Trial of Gemcitabine Plus TH-302 Versus Gemcitabine in Patients With Advanced Pancreatic Cancer. J. Clin. Oncol. Off. J. Am. Soc. Clin. Oncol. 2015, 33, 1475-1481. [CrossRef]

184. Nakashima, H.; Nakamura, M.; Yamaguchi, H.; Yamanaka, N.; Akiyoshi, T.; Koga, K.; Yamaguchi, K.; Tsuneyoshi, M.; Tanaka, M.; Katano, M. Nuclear factor-kappaB contributes to hedgehog signaling pathway activation through sonic hedgehog induction in pancreatic cancer. Cancer Res. 2006, 66, 7041-7049. [CrossRef]

185. Olive, K.P.; Jacobetz, M.A.; Davidson, C.J.; Gopinathan, A.; McIntyre, D.; Honess, D.; Madhu, B.; Goldgraben, M.A.; Caldwell, M.E.; Allard, D.; et al. Inhibition of Hedgehog signaling enhances delivery of chemotherapy in a mouse model of pancreatic cancer. Science 2009, 324, 1457-1461. [CrossRef] 
186. Fu, J.; Rodova, M.; Nanta, R.; Meeker, D.; Van Veldhuizen, P.J.; Srivastava, R.K.; Shankar, S. NPV-LDE-225 (Erismodegib) inhibits epithelial mesenchymal transition and self-renewal of glioblastoma initiating cells by regulating miR-21, miR-128, and miR-200. Neuro Oncol. 2013, 15, 691-706. [CrossRef]

187. Pijnappel, E.N.; Klaassen, R.; van der Lee, K.S.; Pleunis-van Empel, M.; Richel, D.; Legdeur, M.; Nederveen, A.; van Laarhoven, H.W.M.; Wilmink, H.W. Phase I/II study of LDE225 in combination with gemcitabine and nabpaclitaxel in patients with metastatic pancreatic cancer. Ann. Oncol. Submitt. Abstr. Gastrointest. Tumours Non Colorectal 2019, 30, V265. [CrossRef]

188. Richards, D.A.; Stephenson, J.; Wolpin, B.M.; Becerra, C.; Hamm, J.T.; Messersmith, W.A.; Devens, S.; Cushing, J.; Schmalbach, T.; Fuchs, C.S. A phase Ib trial of IPI-926, a hedgehog pathway inhibitor, plus gemcitabine in patients with metastatic pancreatic cancer. J. Clin. Oncol. 2012, 30, 213. [CrossRef]

189. Land, S.C.; Tee, A.R. Hypoxia-inducible factor 1alpha is regulated by the mammalian target of rapamycin (mTOR) via an mTOR signaling motif. J. Biol. Chem. 2007, 282, 20534-20543. [CrossRef] [PubMed]

190. Advani, S.H. Targeting mTOR pathway: A new concept in cancer therapy. Indian J. Med. Paediatr. Oncol. 2010, 31, 132-136. [CrossRef] [PubMed]

191. Iriana, S.; Ahmed, S.; Gong, J.; Annamalai, A.A.; Tuli, R.; Hendifar, A.E. Targeting mTOR in Pancreatic Ductal Adenocarcinoma. Front. Oncol. 2016, 6, 99. [CrossRef]

192. Faes, S.; Planche, A.; Uldry, E.; Santoro, T.; Pythoud, C.; Stehle, J.C.; Horlbeck, J.; Letovanec, I.; Riggi, N.; Datta, D.; et al. Targeting carbonic anhydrase IX improves the anti-cancer efficacy of mTOR inhibitors. Oncotarget 2016, 7, 36666-36680. [CrossRef]

193. Li, M.; Li, X.; Zhang, H.; Lu, Y. Molecular Mechanisms of Metformin for Diabetes and Cancer Treatment. Front. Physiol. 2018, 9, 1039. [CrossRef]

194. Rozengurt, E.; Sinnett-Smith, J.; Kisfalvi, K. Crosstalk between insulin/insulin-like growth factor-1 receptors and $G$ protein-coupled receptor signaling systems: A novel target for the antidiabetic drug metformin in pancreatic cancer. Clin. Cancer Res. Off. J. Am. Assoc. Cancer Res. 2010, 16, 2505-2511. [CrossRef]

195. Dos Santos Guimaraes, I.; Tessarollo, N.G.; Dos Santos, D.Z.; de Souza, M.L.M.; Henriques, T.B.; Silva, I.V.; Rangel, L.B.A. Metformin and mTOR Inhibitors: Allies against Ovarian and Breast Cancers. J. Carcinog. Mutagenesis 2017, 8, 299. [CrossRef]

196. Kordes, S.; Pollak, M.N.; Zwinderman, A.H.; Mathot, R.A.; Weterman, M.J.; Beeker, A.; Punt, C.J.; Richel, D.J.; Wilmink, J.W. Metformin in patients with advanced pancreatic cancer: A double-blind, randomised, placebo-controlled phase 2 trial. Lancet Oncol. 2015, 16, 839-847. [CrossRef]

197. Sadeghi, N.; Abbruzzese, J.L.; Yeung, S.C.; Hassan, M.; Li, D. Metformin use is associated with better survival of diabetic patients with pancreatic cancer. Clin. Cancer Res. Off. J. Am. Assoc. Cancer Res. 2012, 18, 2905-2912. [CrossRef] [PubMed]

198. Wei, S.C.; Duffy, C.R.; Allison, J.P. Fundamental Mechanisms of Immune Checkpoint Blockade Therapy. Cancer Discov. 2018, 8, 1069-1086. [CrossRef] [PubMed]

199. Wu, X.; Gu, Z.; Chen, Y.; Chen, B.; Chen, W.; Weng, L.; Liu, X. Application of PD-1 Blockade in Cancer Immunotherapy. Comput. Struct. Biotechnol. J. 2019, 17, 661-674. [CrossRef] [PubMed]

200. Calcinotto, A.; Filipazzi, P.; Grioni, M.; Iero, M.; De Milito, A.; Ricupito, A.; Cova, A.; Canese, R.; Jachetti, E.; Rossetti, M.; et al. Modulation of microenvironment acidity reverses anergy in human and murine tumor-infiltrating T lymphocytes. Cancer Res. 2012, 72, 2746-2756. [CrossRef]

201. Fischer, K.; Hoffmann, P.; Voelkl, S.; Meidenbauer, N.; Ammer, J.; Edinger, M.; Gottfried, E.; Schwarz, S.; Rothe, G.; Hoves, S.; et al. Inhibitory effect of tumor cell-derived lactic acid on human T cells. Blood 2007, 109, 3812-3819. [CrossRef]

202. Ko, A.H.; Dito, E.; Schillinger, B.; Venook, A.P.; Xu, Z.; Bergsland, E.K.; Wong, D.; Scott, J.; Hwang, J.; Tempero, M.A. A phase II study evaluating bevacizumab in combination with fixed-dose rate gemcitabine and low-dose cisplatin for metastatic pancreatic cancer: Is an anti-VEGF strategy still applicable? Investig. New Drugs 2008, 26, 463-471. [CrossRef]

203. Burtness, B.; Thomas, L.; Sipples, R.; McGurk, M.; Salikooti, S.; Christoforou, M.; Mirto, G.; Salem, R.; Sosa, J.; Kloss, R.; et al. Phase II trial of weekly docetaxel/irinotecan combination in advanced pancreatic cancer. Cancer J. 2007, 13, 257-262. [CrossRef] 
204. Semrad, T.; Barzi, A.; Lenz, H.J.; Hutchins, I.M.; Kim, E.J.; Gong, I.Y.; Tanaka, M.; Beckett, L.; Holland, W.; Burich, R.A.; et al. Pharmacodynamic separation of gemcitabine and erlotinib in locally advanced or metastatic pancreatic cancer: Therapeutic and biomarker results. Int. J. Clin. Oncol. 2015, 20, 518-524. [CrossRef]

205. Shultz, D.B.; Pai, J.; Chiu, W.; Ng, K.; Hellendag, M.G.; Heestand, G.; Chang, D.T.; Tu, D.; Moore, M.J.; Parulekar, W.R.; et al. A Novel Biomarker Panel Examining Response to Gemcitabine with or without Erlotinib for Pancreatic Cancer Therapy in NCIC Clinical Trials Group PA.3. PLoS ONE 2016, 11, e0147995. [CrossRef]

206. Chung, V.; McDonough, S.; Philip, P.A.; Cardin, D.; Wang-Gillam, A.; Hui, L.; Tejani, M.A.; Seery, T.E.; Dy, I.A.; Al Baghdadi, T.; et al. Effect of Selumetinib and MK-2206 vs. Oxaliplatin and Fluorouracil in Patients With Metastatic Pancreatic Cancer After Prior Therapy: SWOG S1115 Study Randomized Clinical Trial. JAMA Oncol. 2017, 3, 516-522. [CrossRef] [PubMed]

207. De Jesus-Acosta, A.; Sugar, E.A.; O’Dwyer, P.J.; Ramanathan, R.K.; Von Hoff, D.D.; Rasheed, Z.; Zheng, L.; Begum, A.; Anders, R.; Maitra, A.; et al. Phase 2 study of vismodegib, a hedgehog inhibitor, combined with gemcitabine and nabpaclitaxel in patients with untreated metastatic pancreatic adenocarcinoma. Br. J. Cancer 2020, 122, 498-505. [CrossRef] [PubMed]

208. Kim, E.J.; Sahai, V.; Abel, E.V.; Griffith, K.A.; Greenson, J.K.; Takebe, N.; Khan, G.N.; Blau, J.L.; Craig, R.; Balis, U.G.; et al. Pilot clinical trial of hedgehog pathway inhibitor GDC-0449 (vismodegib) in combination with gemcitabine in patients with metastatic pancreatic adenocarcinoma. Clin. Cancer Res. Off. J. Am. Assoc. Cancer Res. 2014, 20, 5937-5945. [CrossRef] [PubMed]

209. Catenacci, D.V.; Junttila, M.R.; Karrison, T.; Bahary, N.; Horiba, M.N.; Nattam, S.R.; Marsh, R.; Wallace, J.; Kozloff, M.; Rajdev, L.; et al. Randomized Phase Ib/II Study of Gemcitabine Plus Placebo or Vismodegib, a Hedgehog Pathway Inhibitor, in Patients With Metastatic Pancreatic Cancer. J. Clin. Oncol. Off. J. Am. Soc. Clin. Oncol. 2015, 33, 4284-4292. [CrossRef]

210. Stephenson, J.; Richards, D.A.; Wolpin, B.M.; Becerra, C.; Hamm, J.T.; Messersmith, W.A.; Devens, S.; Cushing, J.; Goddard, J.; Schmalbach, T.; et al. The safety of IPI-926, a novel hedgehog pathway inhibitor, in combination with gemcitabine in patients (pts) with metastatic pancreatic cancer. J. Clin. Oncol. 2011, 29 (Suppl. 15), 4114. [CrossRef]

211. Yao, J.C.; Shah, M.H.; Ito, T.; Bohas, C.L.; Wolin, E.M.; Van Cutsem, E.; Hobday, T.J.; Okusaka, T.; Capdevila, J.; de Vries, E.G.; et al. Everolimus for advanced pancreatic neuroendocrine tumors. N. Engl. J. Med. 2011, 364, 514-523. [CrossRef]

212. Lombard-Bohas, C.; Yao, J.C.; Hobday, T.; Van Cutsem, E.; Wolin, E.M.; Panneerselvam, A.; Stergiopoulos, S.; Shah, M.H.; Capdevila, J.; Pommier, R. Impact of prior chemotherapy use on the efficacy of everolimus in patients with advanced pancreatic neuroendocrine tumors: A subgroup analysis of the phase III RADIANT-3 trial. Pancreas 2015, 44, 181-189. [CrossRef]

213. Yao, J.C.; Pavel, M.; Lombard-Bohas, C.; Van Cutsem, E.; Voi, M.; Brandt, U.; He, W.; Chen, D.; Capdevila, J.; de Vries, E.G.E.; et al. Everolimus for the Treatment of Advanced Pancreatic Neuroendocrine Tumors: Overall Survival and Circulating Biomarkers From the Randomized, Phase III RADIANT-3 Study. J. Clin. Oncol. Off. J. Am. Soc. Clin. Oncol. 2016, 34, 3906-3913. [CrossRef]

214. Weiss, G.J.; Blaydorn, L.; Beck, J.; Bornemann-Kolatzki, K.; Urnovitz, H.; Schutz, E.; Khemka, V. Phase $\mathrm{Ib} / \mathrm{II}$ study of gemcitabine, nabpaclitaxel, and pembrolizumab in metastatic pancreatic adenocarcinoma. Investig. New Drugs 2018, 36, 96-102. [CrossRef]

215. Iikuni, S.; Ono, M.; Watanabe, H.; Shimizu, Y.; Sano, K.; Saji, H. Cancer radiotheranostics targeting carbonic anhydrase-IX with (111)In- and (90)Y-labeled ureidosulfonamide scaffold for SPECT imaging and radionuclide-based therapy. Theranostics 2018, 8, 2992-3006. [CrossRef]

216. Peeters, S.G.; Dubois, L.; Lieuwes, N.G.; Laan, D.; Mooijer, M.; Schuit, R.C.; Vullo, D.; Supuran, C.T.; Eriksson, J.; Windhorst, A.D.; et al. [(18)F]VM4-037 MicroPET Imaging and Biodistribution of Two In Vivo CAIX-Expressing Tumor Models. Mol. Imaging Biol. 2015, 17, 615-619. [CrossRef] [PubMed]

217. Yang, X.; Minn, I.; Rowe, S.P.; Banerjee, S.R.; Gorin, M.A.; Brummet, M.; Lee, H.S.; Koo, S.M.; Sysa-Shah, P.; Mease, R.C.; et al. Imaging of carbonic anhydrase IX with an 111In-labeled dual-motif inhibitor. Oncotarget 2015, 6, 33733-33742. [CrossRef] [PubMed] 
218. Lock, F.E.; McDonald, P.C.; Lou, Y.; Serrano, I.; Chafe, S.C.; Ostlund, C.; Aparicio, S.; Winum, J.Y.; Supuran, C.T.; Dedhar, S. Targeting carbonic anhydrase IX depletes breast cancer stem cells within the hypoxic niche. Oncogene 2013, 32, 5210-5219. [CrossRef] [PubMed]

219. Chamie, K.; Donin, N.M.; Klopfer, P.; Bevan, P.; Fall, B.; Wilhelm, O.; Storkel, S.; Said, J.; Gambla, M.; Hawkins, R.E.; et al. Adjuvant Weekly Girentuximab Following Nephrectomy for High-Risk Renal Cell Carcinoma: The ARISER Randomized Clinical Trial. JAMA Oncol. 2017, 3, 913-920. [CrossRef]

C 2020 by the authors. Licensee MDPI, Basel, Switzerland. This article is an open access article distributed under the terms and conditions of the Creative Commons Attribution (CC BY) license (http://creativecommons.org/licenses/by/4.0/). 